Departement für Kleintiere, Klinik für Zoo-, Heim- und Wildtiere der Vetsuisse-Fakultät Universität Zürich

Direktor: Prof. Dr. J.-M. Hatt

Arbeit unter wissenschaftlicher Betreuung von

Prof. Dr. M. Clauss

\title{
Seasonal Mortality in Zoo Ruminants
}

\section{Inaugural-Dissertation}

zur Erlangung der Doktorwürde der

Vetsuisse-Fakultät Universität Zürich

vorgelegt von

\section{Lea Carisch}

Tierärztin

von Andiast, Graubünden

genehmigt auf Antrag von

Prof. Dr. M. Clauss, Referent 
Departement für Kleintiere, Klinik für Zoo-, Heim- und Wildtiere der Vetsuisse-Fakultät Universität Zürich

Direktor: Prof. Dr. J.-M. Hatt

Arbeit unter wissenschaftlicher Betreuung von

Prof. Dr. M. Clauss

\section{Seasonal Mortality in Zoo Ruminants}

\section{Inaugural-Dissertation}

zur Erlangung der Doktorwürde der

Vetsuisse-Fakultät Universität Zürich

vorgelegt von

\section{Lea Carisch}

Tierärztin

von Andiast, Graubünden

genehmigt auf Antrag von

Prof. Dr. M. Clauss, Referent 
Meinen Eltern 


\section{Inhaltsverzeichnis}

Zusammenfassung/Summary $\quad 1$

Publikation Zoo Biology $\quad 2$

Abstract 2

Introduction $\quad 2$

Methods 3

$\begin{array}{ll}\text { Results } & 6\end{array}$

Basic Patterns Among and Across Species $\quad 6$

Husbandry, Biological, and Environmental Factors $\quad 8$

$\begin{array}{lr}\text { Timing of Seasonal Mortality } & 8\end{array}$

$\begin{array}{ll}\text { Discussion } & 10\end{array}$

$\begin{array}{ll}\text { Seasonal Mortality and Life Expectancy } & 10\end{array}$

Seasonal Mortality, Climate, and Geographic Species Origin 10

$\begin{array}{ll}\text { Seasonal Mortality and Reproductive Biology } & 12\end{array}$

$\begin{array}{ll}\text { Conclusions } & 12\end{array}$

$\begin{array}{ll}\text { References } & 13\end{array}$

Supporting information $\quad 15$

$\begin{array}{ll}\text { Lebenslauf } & 26\end{array}$

$\begin{array}{ll}\text { Danksagung } & 27\end{array}$ 


\section{Zusammenfassung}

Saisonale Mortalität bei Zoo-Wiederkäuern

In unserer Studie untersuchten wir die saisonale Mortalität bei Wildwiderkäuern in zoologischen Gärten mit Daten von 60'591 Individuen und 88 Spezies und definierten dafür die saisonale Mortalität durch die 3 aufeinanderfolgenden Monate mit der höchsten über der BasisMortalität liegenden Mortalität (3MM). 3MM zeigte keinen signifikanten Zusammenhang zu der relativen Lebenserwartung; die saisonale Mortalität beeinflusst den Haltungserfolg also nicht. Es bestand kein Zusammenhang zwischen den Breitengraden der ursprünglichen Herkunft der Spezies oder der durchschnittlichen Jahrestemperatur im Ursprungs-Habitat und 3MM. Spezies aus tieferen Breitengraden und somit wärmeren Klimazonen sind also wider Erwarten nicht anfälliger für saisonale Mortalität in Zoos. 3MM zeigte einen signifikanten Zusammenhang mit der Reproduktion. Dieses Muster war bei den Wiederkäuer-Familien unterschiedlich: Bei Cerviden war der Beginn der saisonalen Mortalität bei beiden Geschlechtern mit dem Beginn der Brunft verknüpft. Bei den Boviden hing hingegen bei einer Gruppe von Spezies (hauptsächlich Capriden) der Beginn der saisonalen Mortalität eng mit der Geburtssaison zusammen. Während die Herkunft einer Spezies aus wärmeren Klimazonen den Haltungserfolg von Wildwiederkäuern nicht durch eine erhöhte saisonale Mortalität beeinträchtigt, sollten Massnahmen zum Schutze der weiblichen vor den männlichen Tieren während der Brunft insbesondere bei den Hirschartigen eine wichtige Rolle spielen.

Ruminantia, Wiederkäuer, Saisonalität, Reproduktion, Klima, Haltung, Mortalität

\section{Summary}

\section{Seasonal Mortality in Zoo Ruminants}

We investigated whether a seasonal signal of mortality exists in wild ruminants kept in zoos, using data from 60,591 individuals of 88 species. We quantified the mortality in the 3 consecutive months with the highest above-baseline mortality (3 MM). 3MM was not related to relative life expectancy of species, indicating that seasonal mortality does not necessarily impact husbandry success. Although 3MM was mainly observed in autumn/winter months, there was no evidence for an expected negative relationship with the latitude of the species' natural habitat and no positive relationship between $3 \mathrm{MM}$ and the mean temperature in that habitat, indicating no evidence for species from lower latitudes/warmer climates being more susceptible to seasonal mortality under zoo conditions. $3 \mathrm{MM}$ was related to reproductive biology, with seasonally reproducing species also displaying more seasonal mortality. This pattern differed between groups: In cervids, the onset of seasonal mortality in both sexes appeared linked to the onset of rut. This was less evident in bovids, where in a number of species (especially caprids), the onset of female seasonal mortality was linked to the lambing period. While showing that the origin of a species from warmer climate zones does not constrain husbandry success in ruminants in terms of an increased seasonal mortality, the results suggest that husbandry measures aimed at protecting females from rutting males are important, especially in cervids.

ruminant; seasonality; reproduction; climate; husbandry; mortality 


\title{
RESEARCH ARTICLE
}

\section{Seasonal Mortality in Zoo Ruminants}

\author{
Lea Carisch, ${ }^{1}$ Dennis W. H. Müller, ${ }^{2}$ Jean-Michel Hatt, ${ }^{1}$ Laurie Bingaman Lackey, ${ }^{3}$ \\ E. Eberhard Rensch, ${ }^{1}$ Marcus Clauss, ${ }^{1 \star}$ and Philipp Zerbe ${ }^{1}$
}

\author{
${ }^{1}$ Clinic for Zoo Animals, Exotic Pets and Wildlife, Vetsuisse Faculty, University of Zurich, Zurich, Switzerland \\ ${ }^{2}$ Zoologischer Garten Halle GmbH, Halle, Germany \\ ${ }^{3}$ World Association of Zoos and Aquariums (WAZA), Gland, Switzerland
}

\begin{abstract}
While seasonality has often been investigated with respect to reproduction, seasonality of mortality has received less attention. We investigated whether a seasonal signal of mortality exists in wild ruminants kept in zoos, using data from 60,591 individuals of 88 species. We quantified the mortality in the 3 consecutive months with the highest above-baseline mortality (3 MM). $3 \mathrm{MM}$ was not related to relative life expectancy of species, indicating that seasonal mortality does not necessarily impact husbandry success. Although $3 \mathrm{MM}$ was mainly observed in autumn/winter months, there was no evidence for an expected negative relationship with the latitude of the species' natural habitat and no positive relationship between $3 \mathrm{MM}$ and the mean temperature in that habitat, indicating no evidence for species from lower latitudes/warmer climates being more susceptible to seasonal mortality under zoo conditions. $3 \mathrm{MM}$ was related to reproductive biology, with seasonally reproducing species also displaying more seasonal mortality. This pattern differed between groups: In cervids, the onset of seasonal mortality appeared linked to the onset of rut in both sexes. This was less evident in bovids, where in a number of species (especially caprids), the onset of female seasonal mortality was linked to the lambing period. While showing that the origin of a species from warmer climate zones does not constrain husbandry success in ruminants in terms of an increased seasonal mortality, the results suggest that husbandry measures aimed at protecting females from rutting males are important, especially in cervids. Zoo Biol. 36:74-86, $2017 . \quad$ @ 2016 Wiley Periodicals, Inc.
\end{abstract}

Keywords: ruminant; seasonality; reproduction; climate; husbandry; mortality

\section{INTRODUCTION}

The effect of seasonality has been investigated in relation to many aspects of life history traits of free-ranging animals [Moen, 1978; Bronson, 1989; Zerbe et al., 2012]. However, systematic investigations focussing on the impact of seasons on patterns of adult mortality are mainly limited to primates [Otis et al., 1981; Gogarten et al., 2012]. While common sense suggests that there should be, for example, a mortality peak in free-ranging ruminants in temperate zones towards the end of the winter season, corresponding evidence is rarely found in studies focussing on seasonality but mostly reported as a side finding of studies focussing on a variety of aspects of mortality [e.g. McNay and Voller, 1995; Aguirre et al., 1999; DePerno et al., 2000; DelGiudice et al., 2002]. In tropical environments, seasonal mortality may be linked to the rainy season [Milton, 1990] and the corresponding challenge for thermoregulation. In savanna habitats, seasonal mortality is linked to the dry season [Fryxell, 1987; Cronje et al., 2002]. Typically, seasonal mortality is correlated to the severity of the climate conditions of the respective season and ultimately linked to starvation and the depletion of body fat reserves [Fryxell, 1987; Gonzalez and Crampe, 2001; DelGiudice et al., 2002].

Other clusters of mortality risks for adult animals include the rutting season for males as well as the season of late gestation and birth for females in seasonally reproducing species [Gavin et al., 1984]. Additionally, some species' rutting activities may pose an increased mortality risk for females [Reale et al., 1996]. Natural predation, car accidents, and hunting by humans are important additional factors for

Conflict of interest: None.

${ }^{*}$ Correspondence to: Marcus Clauss, Clinic for Zoo Animals, Exotic Pets and Wildlife, Vetsuisse Faculty, University of Zurich, Winterthurerstr. 260, 8057 Zurich, Switzerland,

E-mail: mclauss@vetclinics.uzh.ch

Received 22 July 2016; Revised 31 October 2016; Accepted 08 November 2016

DOI: $10.1002 /$ zoo.21337

Published online 15 November 2016 in Wiley Online Library (wileyonlinelibrary.com). 
the timing of mortality in free-ranging ungulates, although the latter ones represent anthropogenic factors. Seasonal peaks of mortality by predation will often follow that of energetically expensive periods such as seasons of food shortage (winter, dry season) or rut, because of the higher vulnerability of prey during such periods [Owen-Smith, 2008], and car accidents may show peaks in parallel to rutting activity [Allen and McCullough, 1976]. Seasonal mortality due to hunting is indeed the effect of respective hunting seasons [Nelson and Mech, 1986].

For domestic hoofstock, investigations of seasonal mortality have produced variable results. In dairy cattle, several studies found higher mortalities during the summer months [Vitali et al., 2009; Crescio et al., 2010; Alvåsen et al., 2012; Morignat et al., 2015], suggesting a particular relevance of heat stress in cattle, but temperatures below a cold threshold have also been related to increased mortality [Morignat et al., 2015]. Farmed sheep in a temperate climate environment had increased mortalities around the lambing period, but also succumbed to predation particularly in winter [Nass, 1977]. Seasonal differences in the occurrence of parasite development stages and hence parasite infestations can play an additional role [e.g., Nwosu et al., 2007].

Zoological gardens are protected environments that shelter their animals against climatic extremes, predators, diseases, or shortages in food supply. In theory, therefore, any seasonality signal in the mortality pattern in zoos should be less pronounced compared to the wild. Nevertheless, a seasonal mortality signal could be expected in zoos, in parallel to observations made on domestic animal populations. However, even though experiences such as a 'winter death syndrome' in deer are recognized [Flach, 2008], studies on the seasonality of mortality are rare in zoo animals. To our knowledge, the only study of a population of zoo animals referred to ruminants [Gull et al., 2010]. The study was conducted in a private zoo in the Middle-East. However, the expectation that the hot dry summers of the region might be particularly related to mortality peaks was not corroborated. Instead, mortality peaked during more humid and windy months of colder temperatures.

In the present study, we expanded this approach to ruminant species kept in zoos around the world. We particularly expected mortality peaks in the winter months in species originating from warmer and/or dryer climate zones, or in association with the rutting or the birthing season in highly seasonally reproducing species. The following predictions guided our approach:

1. There are differences in the degree of seasonal mortality between species, and between the sexes of species.

2. If seasonal mortality is not a major contributing factor to the general husbandry success, there should be no relationship between the degree of seasonal mortality of species and their relative life expectancy.

3. Whether species display a seasonal mortality pattern may depend on adaptations to climate or to seasonal reproduction events (such as rut or birth). In particular, mortality in animals from lower latitudes and thus warmer climate zones might be higher during winters in temperature zone zoos. Due to possible difficulties in providing browsers with natural forage during winter [Clauss and Dierenfeld, 2008], browsing species might be particularly susceptible to seasonal mortality. Such cases would represent a zoospecific seasonal mortality. Factors related to seasonal reproduction, such as mating system (monogamous vs. polygamous) or length of the rutting period, might have an effect on mortality; in such cases, seasonal mortality in zoos would probably mirror seasonal mortality in the wild. If no biological characteristics can be identified that correlate with seasonal mortality, then the pattern might simply reflect an effect of season/climate that affects animals in a general way.

4. In species with a highly seasonal mortality and no difference in the mortality pattern between the sexes, this indicates either a) an effect of climate (with a peak mortality in winter); as this would be expected for species not adapted to a temperate seasonal environment, such species should mainly stem from lower latitudes and thus warmer climate zones; or b) an effect of a rutting season (i.e., in species with a highly seasonal reproduction) where stress during the rut affects both males and females. This case would suggest that husbandry measures to protect females during the rut should be intensified.

5. In species with a highly seasonal mortality and a distinct difference in the mortality pattern between the sexes, this indicates different effects, most likely that of rut on males and that of winter or birthing period in females.

\section{METHODS}

We analysed data for species of captive wild ruminants from Species360 (the former International Species Information System (ISIS)) data files [Müller et al., 2011; Zerbe et al., 2012], covering a range of more than 40 years (from 1970 to 2013) from more than 800 zoological institutions. In order to retain the seasonal signal, the dates of death from individuals kept in the southern hemisphere were adjusted, adding 6 months. For each species, the numbers of deaths per month were evaluated for males and females separately, in all specimens that had reached at least an age of 2 years. This was done because selective culling, particular in surplus males, typically occurs within the first 2 years of life in ruminants [Müller et al., 2010]. As we observed a gross overrepresentation of deaths noted for the 1st of January and the 31 st of December, counts for these days were discarded, assuming that they represented entries in the database intended for the year without specification of the exact death date. Subsequently, we excluded species with less than 50 remaining data for either males or females in the database, resulting in a sample of 88 species, ranging from 108 to 3,166 individuals per species.

For each species and sex, we expressed the deaths of each month in $\%$ of the total death count of all months. To 
summarize individual species into larger taxonomic groups (such as families), the average of all species (not individuals) that relate to the respective group was used.

First, the resulting patterns were plotted and categorized subjectively into five categories: (1) a clear $\mathrm{V}$ - or inverted V- pattern with clear nadir and peak; (2) a more U- or inverted U-pattern with a lower nadir and broader peak; (3) a vague pattern with a single low nadir or peak but without mortalities of other months leading towards these; (4) two separate peaks; (5) no seasonal pattern. Subsequently, the mortality in the month with the lowest proportion of deaths was defined as "baseline mortality," and subtracted from the mortalities of all individual months (Fig. 1). The total baseline mortality (BL) therefore is the proportion of the numbers of deaths in the month with the lowest death count multiplied by 12 . We consider BL as the percentage of deaths that occur independently from seasonal influences throughout the year. The additional deaths were used in the assessment of a seasonal pattern, and expressed for each month as the
1

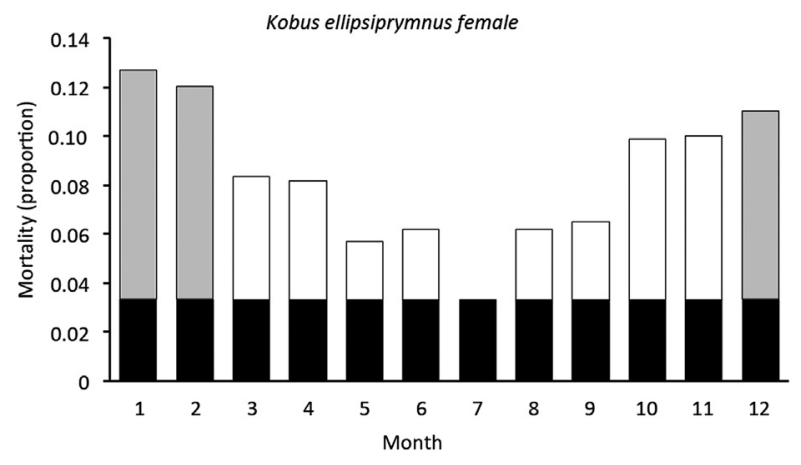

3

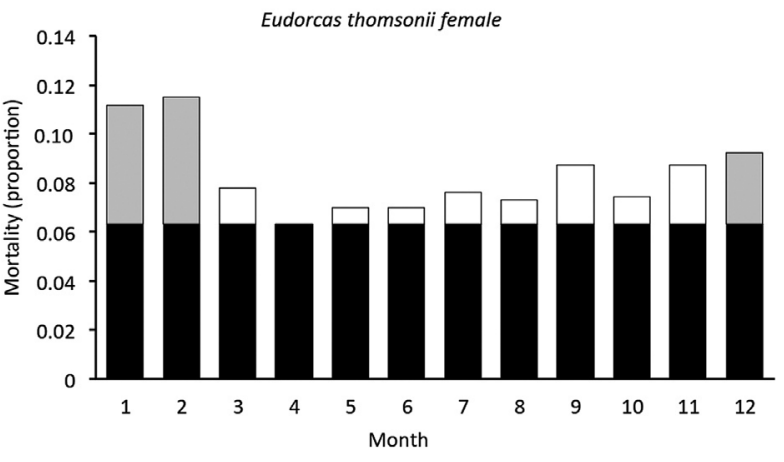

2

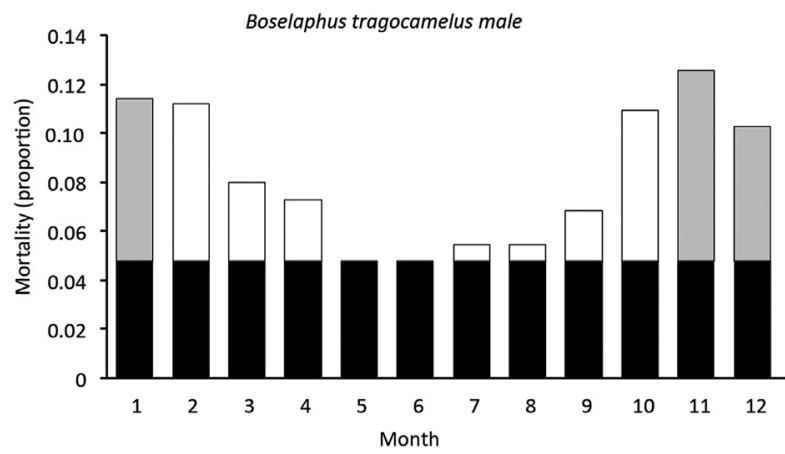

4

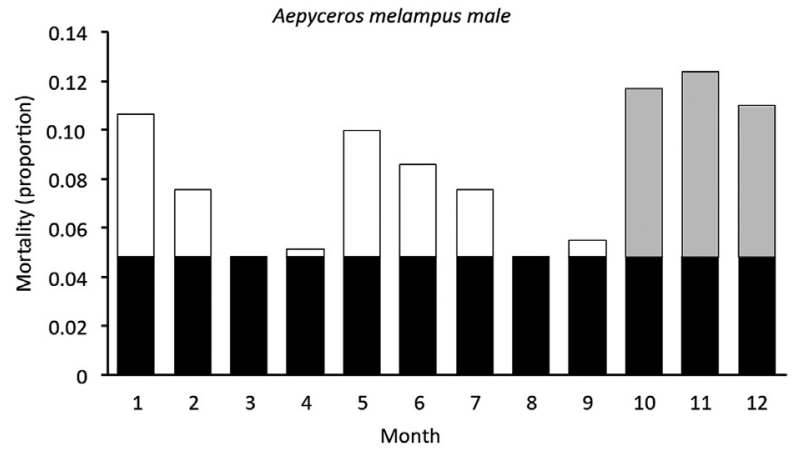

5

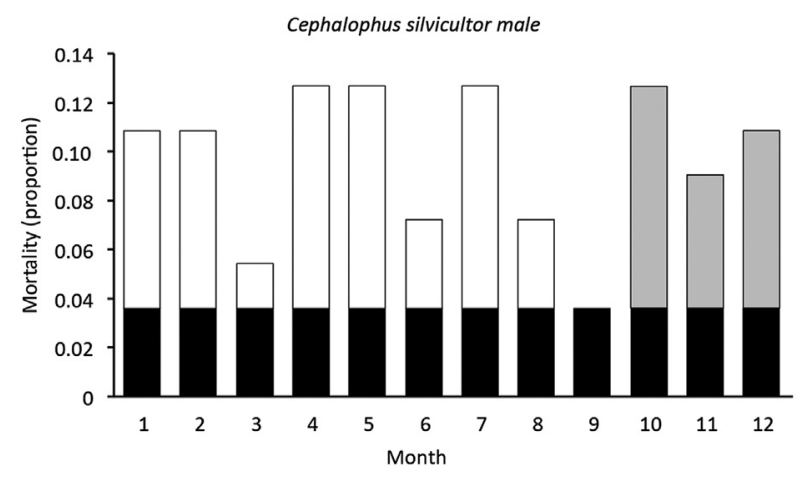

Fig. 1. Categories of seasonal mortality (as a proportion of all deaths) in captive wild ruminants. (1) V- or inverted V-pattern with clear nadir and peak; (2) U- or inverted U- pattern with a lower nadir and broader peak; (3) vague pattern with a single low nadir or peak but without mortalities of other months leading towards these; (4) two separate peaks; (5) no seasonal pattern. The black column parts represent the baseline mortality (i.e., the mortality in the month of the lowest mortality); the light column parts represent the above-baseline mortality, of which the 3 consecutive months with the highest proportion of above-baseline mortality were used as the 3-month-mortality (3 MM, expressed in $\%$ of above-baseline mortality, indicated by the grey shading) to quantify the seasonal mortality. 
proportion of the total above-BL mortality; above-BL mortality was thus zero for the month of the lowest mortality. A set of cross platform command line scripts was developed (in PHP and Swift) to calculate BL, monthly above-BL mortality, the proportion of above-BL deaths that occur in the three consecutive months with the highest number of deaths, and to record the start month of this 3 -month interval of highest mortality. This proportion of above-BL deaths was termed the 3-month-mortality ( $3 \mathrm{MM}$ ). If all above-BL deaths occurred in 3 consecutive months, $3 \mathrm{MM}$ would be 1 ; if the same number of deaths occurred in all months, there would be no above-BL deaths and $3 \mathrm{MM}$ would be 0 ; for a random distribution of aboveBL deaths, $3 \mathrm{MM}$ would be 0.25 .

As a measure of whether the seasonal mortality pattern was similar or dissimilar between the sexes, the nonparametric correlation coefficient was calculated for the correlation between the monthly above-BL mortalities for males and females of a species $\left(\rho_{\mathrm{mf}}\right)$ (Fig. 2A and B). The higher $\rho_{\mathrm{mf}}$, the more similar the pattern between the two sexes. All original metrics collected in the present study for the individual species and sexes are given in Table S2.

Using Jones et al. [2009], Müller et al. [2011], and Zerbe et al. [2012] as starting point, additional data characterizing the individual species were taken from the literature. The dataset includes the adult body mass, the midrange, and maximum latitude of a species' natural range of occurrence, the relative life expectancy (rLE) in captivity as a measure of husbandry success [Müller et al., 2011], the breadth of the peak in which $50 \%$ of all births occur in captivity (birth peak breadth 50-BPB50) as a measure of the degree of reproductive seasonality [Zerbe et al., 2012], the Julian start
A
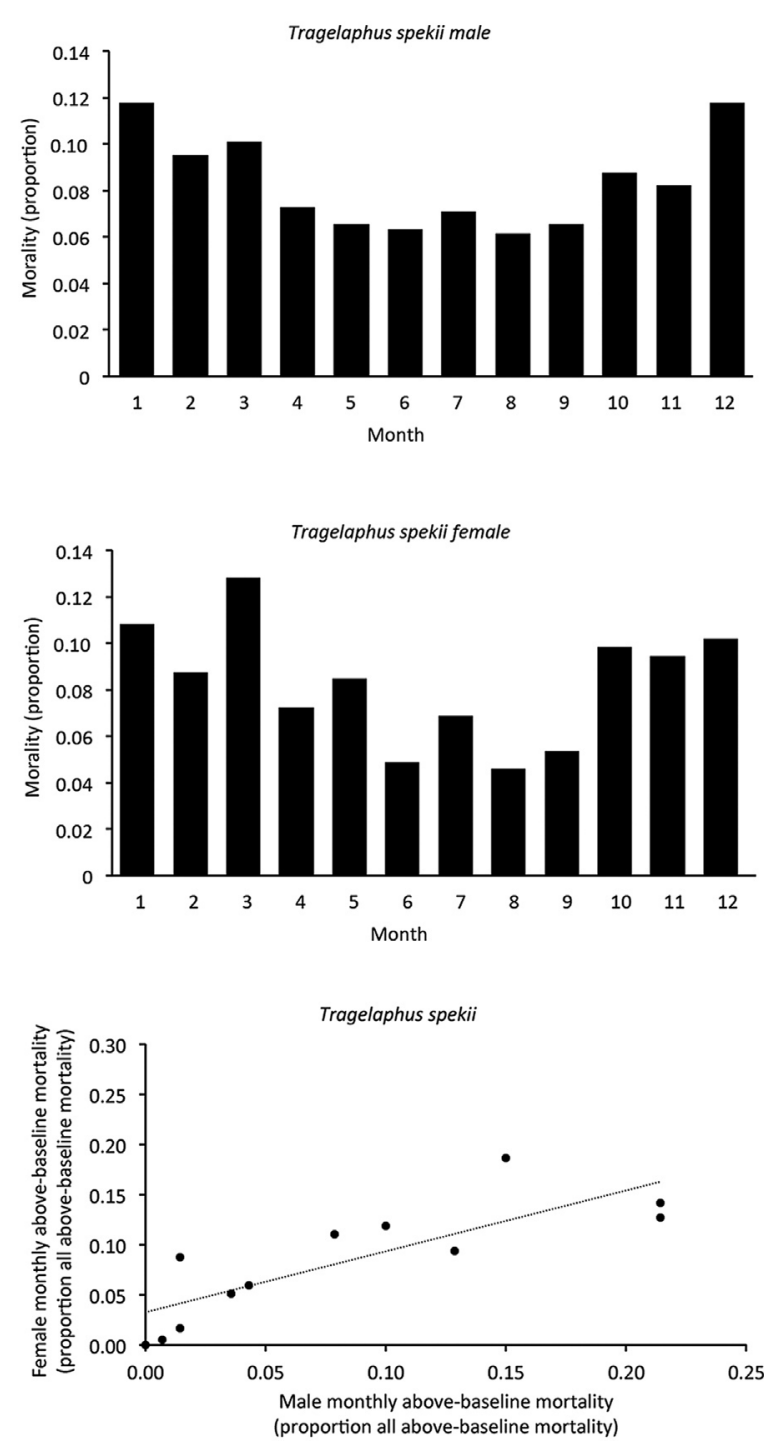

B
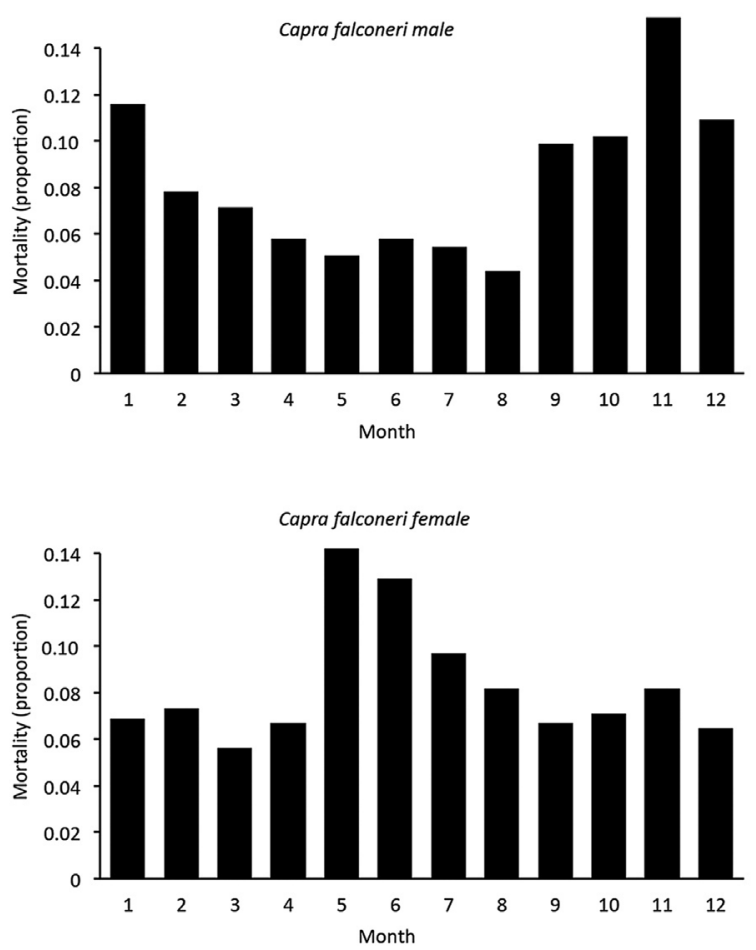

Capra falconer

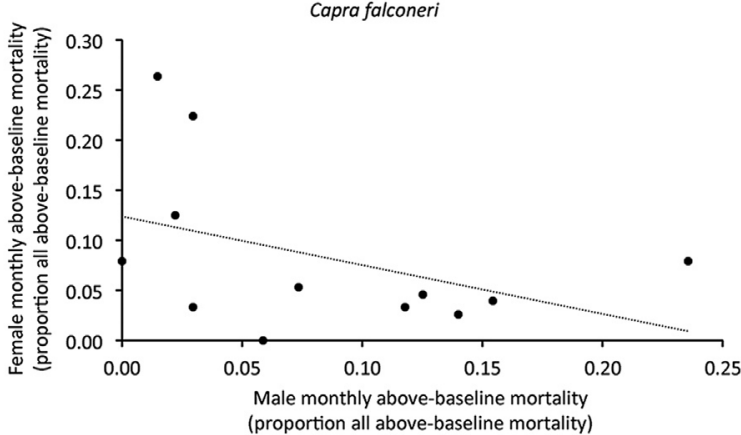

Fig. 2. Examples for a high (A) and a low (B) correlation between the monthly above-baseline mortality (proportion of all above baseline mortality) of males and females $\left(\rho_{\mathrm{mf}}\right)$ in captive (A) sitatunga (Tragelaphus spekii) and (B) markhor (Capra falconeri). 
day of BPB50 and the start day of the corresponding mating season in captivity, mating type, sexual size dimorphism, breeding group size, percent of grass in the natural diet, the annual temperature, and the mean annual precipitation in the natural habitat of the species. These data and the respective sources are collated in Table S1.

For statistical analyses, body mass and sexual size dimorphism were log-transformed to achieve normal distribution. Analyses were performed with Ordinary Least Squares (OLS) and Phylogenetic Generalized Least Squares (PGLS). For PGLS, data were linked to a supertree of extant mammals with branch lengths [Fritz et al., 2009]. The phylogenetic signal $\lambda$ was estimated using maximum likelihood [Revell, 2010]. $\lambda$ can vary between 0 (no phylogenetic signal) and 1 (the observed pattern is predicted by the phylogeny; similarity among species scales in proportion to their shared evolutionary time) [Pagel, 1999; Freckleton et al., 2002]. Results of PGLS analyses were only reported if $\lambda$ was significantly different from 0 , which was rarely the case in our dataset. Results are therefore given for OLS analyses unless specifically noted. Although we submitted the same data to repeated testing, as when analyzing all ruminants and then cervids or bovids alone, we did not correct for multiple testing, because we do not consider the results of equal value: If, for example, a finding is significant in all ruminants and in bovids, we consider this as an indication that the bovids are mainly responsible for the result in all species (and not that both results are equally valuable).

Variables of reproductive strategy (mating type, sexual size dimorphism, breeding group size) were assessed by including them first in models that related $3 \mathrm{MM}$ to body mass, and in models without body mass. Models were compared for goodness-of-fit using Akaike's Information Criterion (AIC). Following guidelines published for wildlife research, we selected as best-supported models those with a $\Delta$ AIC score of $\leq 2$, where $\triangle \mathrm{AIC}=\mathrm{AIC}-$ minimum AIC within the candidate model set [Burnham and Anderson, 2001, 2002]. Models using these variables but excluding body mass were always the best-supported, so only results relating to these models are presented.

A

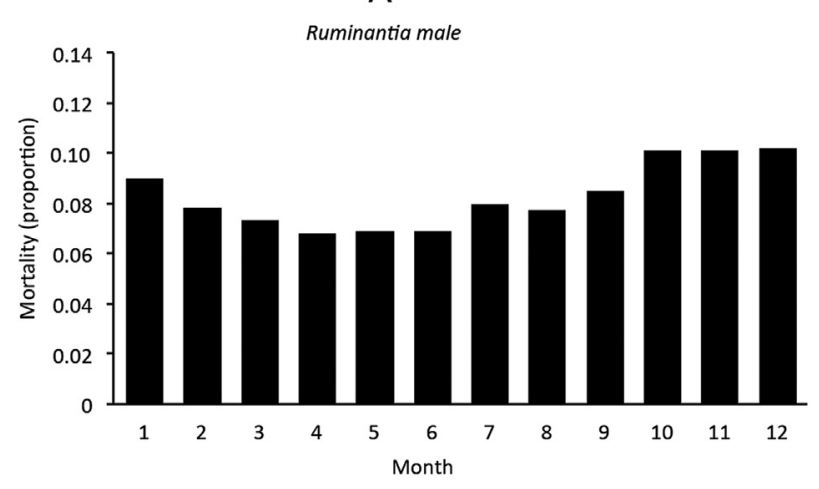

"Seasonal" species in terms of their mortality were defined as those species in which the $3 \mathrm{MM}$ was higher than 0.40. "Seasonal" species in terms of their reproductive biology were defined as those species of seasonality categories 1-3 in captivity [Zerbe et al., 2012]. Several analyses were confined to these subsets of "seasonal" species only. Statistical tests were performed in $R$ 2.15.0 [Team, 2011] using the packages caper [Orme et al., 2010] and nlme [Pinheiro et al., 2011]. All analyses were performed for the whole ruminant dataset, and for cervids and bovids individually. The significance level was set to 0.05 .

\section{RESULTS}

The resulting categories and measures of $\mathrm{BL}$ and $3 \mathrm{MM}$ for species and sexes as well as the $\rho_{\mathrm{mf}}$ are collated in Table S2. Baseline mortality averaged, across all species, at $0.51 \pm 0.16$ for males and $0.55 \pm 0.18$ in females.

\section{Basic Patterns Among and Across Sexes}

Across all ruminant species, a seasonal mortality signal was evident in males, with an increase during the winter period; this pattern was much less distinct for females (Fig. 3). In the individual ruminant families, a similar pattern was evident in tragulids, giraffids, cervids, and bovids; however, antilocaprids (monotypic family: Pronghorn Antilocapra americana) showed a different pattern, with a peak seasonal mortality in late summer (Fig. S1).

There were large differences in the patterns of seasonal mortality between the sexes. In some species where both sexes had a seasonal mortality pattern, $\rho_{\mathrm{mf}}$ was high with a maximum of 0.93 (Tragelaphus spekii, Fig. 2A), indicating that the pattern was similar between the sexes. In other species with a seasonal mortality pattern in both sexes, $\rho_{\mathrm{mf}}$ was low with a minimum of -0.46 (Capra falconeri, Fig. 2B), indicating the opposite.

There was a significant relationship between $3 \mathrm{MM}$ and the categorical classification of seasonal mortality (Table 1); nevertheless, large $3 \mathrm{MM}$ ranges were observed within each category (Fig. S2A). Similarly, there was a

Fig. 3. Monthly mortality of 88 captive wild ruminant species (A) males and (B) females. 


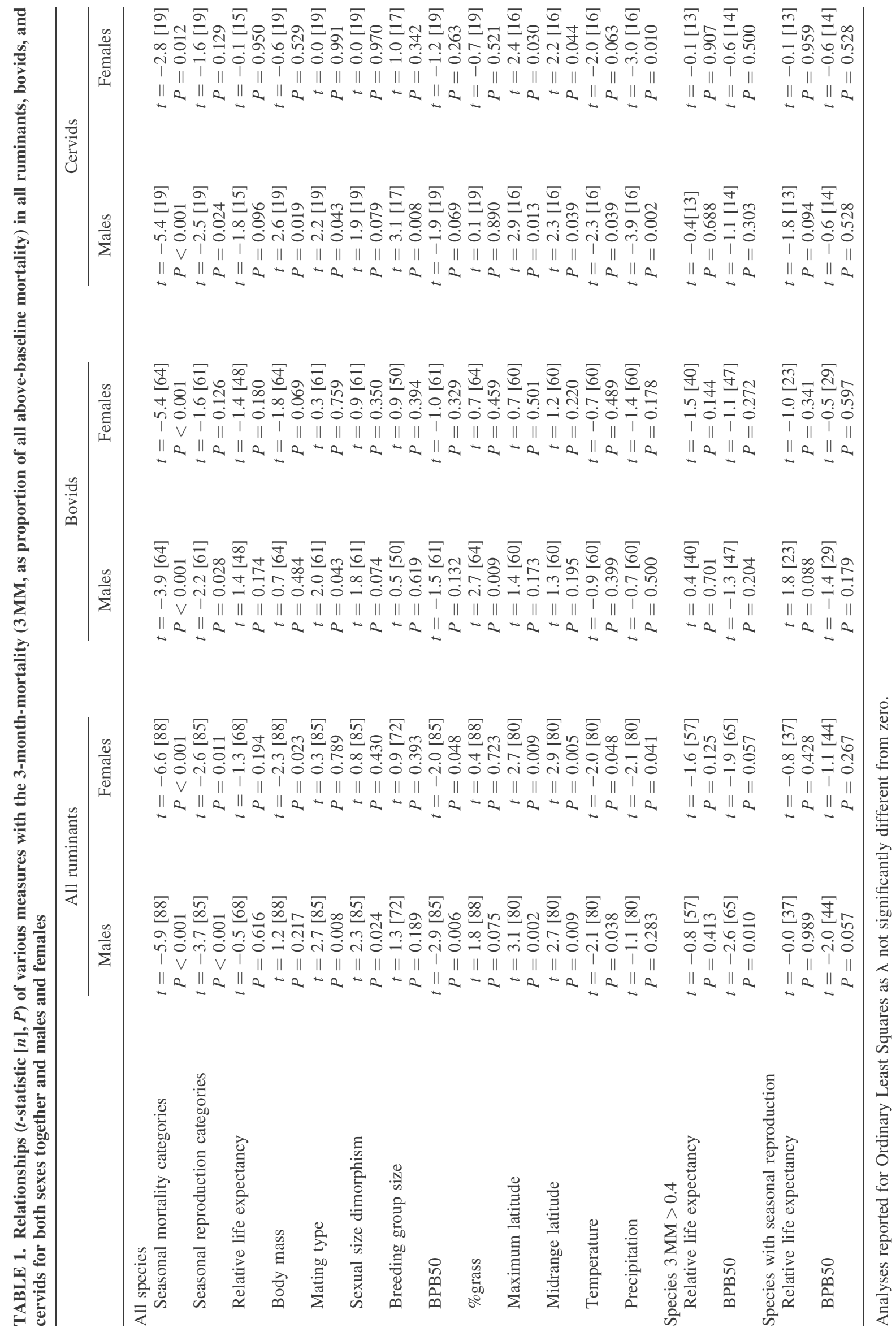


significant relationship between the $3 \mathrm{MM}$ and the categorical classification of Zerbe et al. [2012] for the seasonality of reproduction (Fig. S2B, Table 1). The starting month of the $3 \mathrm{MM}$ block was mostly in late autumn and winter and similar between the sexes in cervids, but was more evenly distributed across the year in female as compared to male bovids (Fig. S3A and B).

\section{Husbandry, Biological, and Environmental Factors}

There was no significant relationship between the $3 \mathrm{MM}$ and the relative life expectancy of males or females in captivity, respectively - neither in all ruminants $(P \geq 0.194)$, nor within bovids $(P \geq 0.174)$, nor within cervids $(P \geq 0.096$, Table 1). Body mass was negatively related to $3 \mathrm{MM}$ in female ruminants $(P=0.023)$ and positively in male cervids $(P=0.019$, Table 1$)$. When combining body mass with either mating type, sexual size dimorphism, or breeding group size, the resulting models often indicated significance of the additional factor; when removing body mass, the resulting AIC of these models (that contained only mating type, or sexual size dimorphism, or breeding group size) was always distinctively lower than when body mass was included. In models using only these descriptors of reproductive biology, $3 \mathrm{MM}$ was positively related to mating type in male ruminants $(P=0.008$, Fig. 4$)$ as well as in male bovids and cervids $(P=0.043$, Table 1$) ; 3 \mathrm{MM}$ was positively related to sexual size dimorphism in male ruminants $(P=0.024)$ and in male cervids $(P=0.019$, Table 1$)$; and $3 \mathrm{MM}$ was positively related to breeding group size in male cervids $(P=0.008$, Table 1$)$. Correspondingly, the BPB50 was negatively related to $3 \mathrm{MM}$ in male $(P=0.006)$ and female $(P=0.048)$ ruminants (Table 1$)$.

The percentage of grass in the natural diet had a positive relationship with $3 \mathrm{MM}$ in male bovids $(P=0.009$, Table 1). There was a positive relationship between $3 \mathrm{MM}$ and both maximum and midrange latitude in male and female ruminants $(P \leq 0.009$, Fig. 5A) and cervids $(P \leq 0.044$, Table 1). Both the mean annual temperature in the natural habitat $(P \leq 0.048$, Fig. 5B) and the mean annual

A

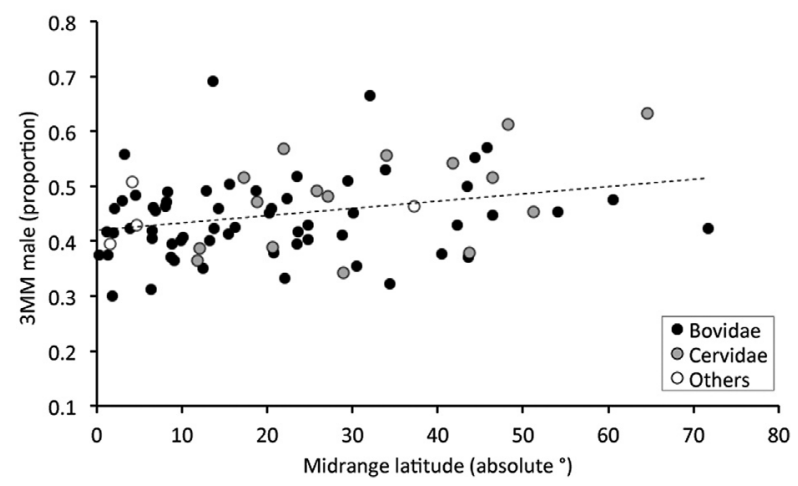

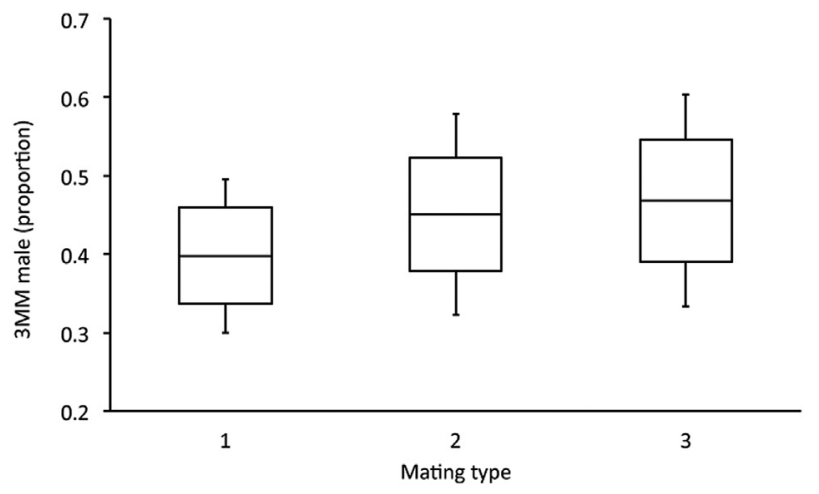

Fig. 4. Comparison of mating type categories (1 monogamous, 2 tending, 3 polygamous) and the 3 -month-mortaliy (3 MM, mean $\pm \mathrm{SD}$, minimum-maximum) as a measure of seasonal mortality in males of captive wild ruminant species.

precipitation in the natural habitat $(P=0.041$ in females $)$ showed the corresponding negative relationships with $3 \mathrm{MM}$ (Table 1). In the dataset, there were negative relationships between midrange latitude and both mean annual temperature and mean annual precipitation $(P<0.001)$. When restricting the dataset to species displaying a seasonal mortality, there still was no significant relationship between $3 \mathrm{MM}$ and $\mathrm{rLE}(P \geq 0.125)$, and $3 \mathrm{MM}$ still had a negative relationship with the BPB50 in male ruminants $(P=0.010$, Table 1).

\section{Timing of Seasonal Mortality}

When plotting the starting date of the mating season or the birthing season against the start month of the $3 \mathrm{MM}$ (Fig. 6), seasonal mortality in males of seasonally reproducing species often started at the end of summer/ beginning of autumn in parallel with the start of their breeding season, whereas the aseasonally reproducing species typically start with their seasonal mortality in winter (Fig. 6A). There appears to be a relationship in seasonally reproducing males between the start of the rut and the start of the $3 \mathrm{MM}$ (Fig. 6B), including a few species that actually do

B

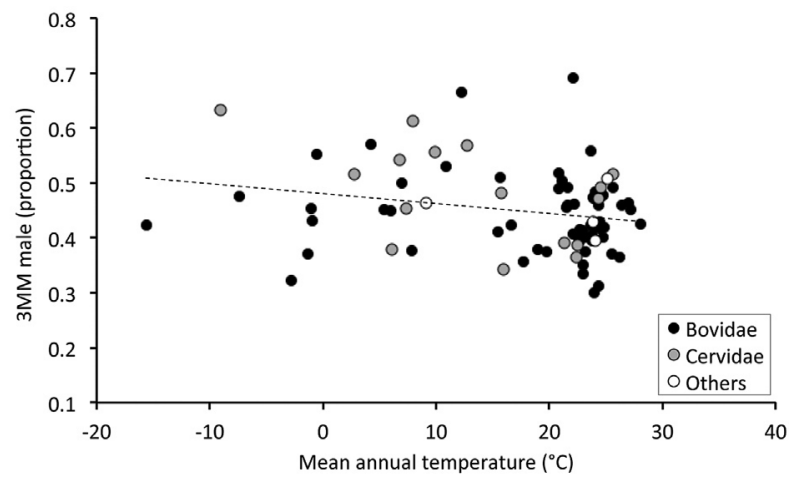

Fig. 5. Relationship of (A) the midrange latitude (as absolute ${ }^{\circ}$ ) and (B) the mean annual temperature with the 3-month-mortality in males of captive wild ruminant species. Regression lines indicated for all ruminants. 
not rut between the end of summer and the beginning of winter. In contrast, the difference between seasonally and aseasonally reproducing species was more distinct in females, where again in aseasonally reproducing species seasonal mortality started in winter (Fig. 6C and E). In contrast, in seasonally reproducing species seasonal mortality started at various times of the year. In many species, seasonal mortality of females started about the same time as the mating season (Fig. 6D, upper right quadrant), but in a number of species, the two events were clearly separated
A

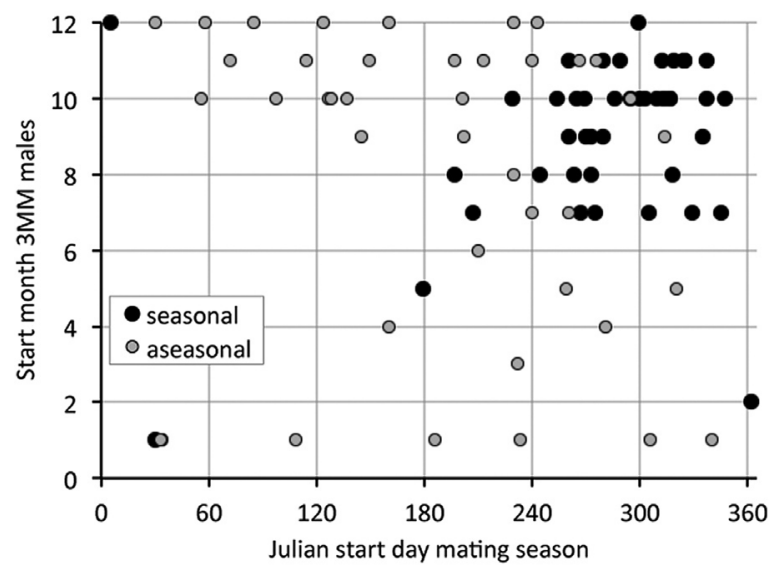

C

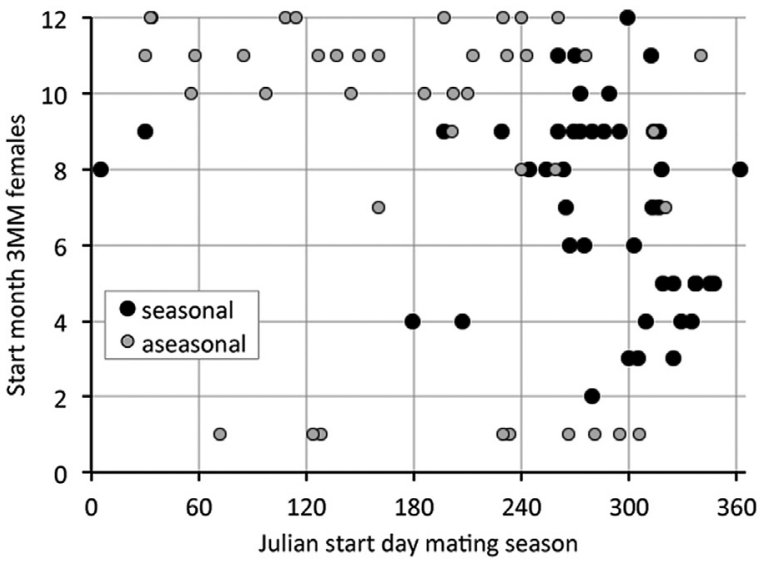

E

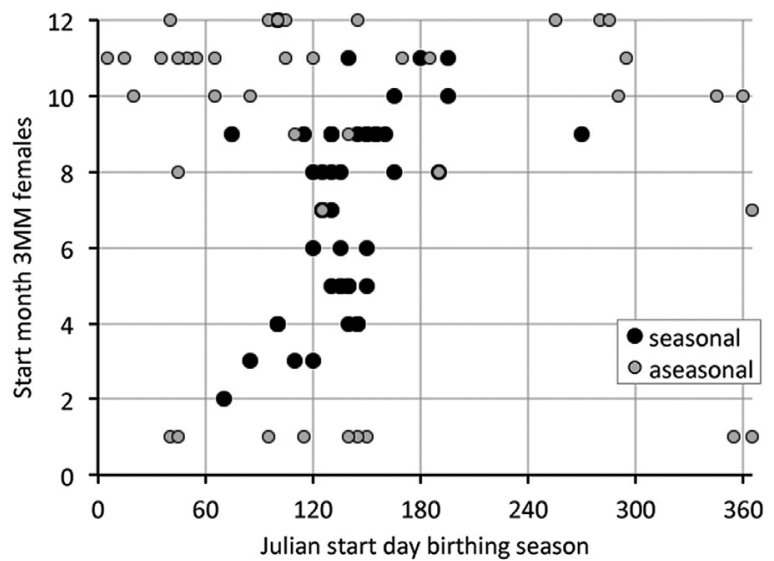

B

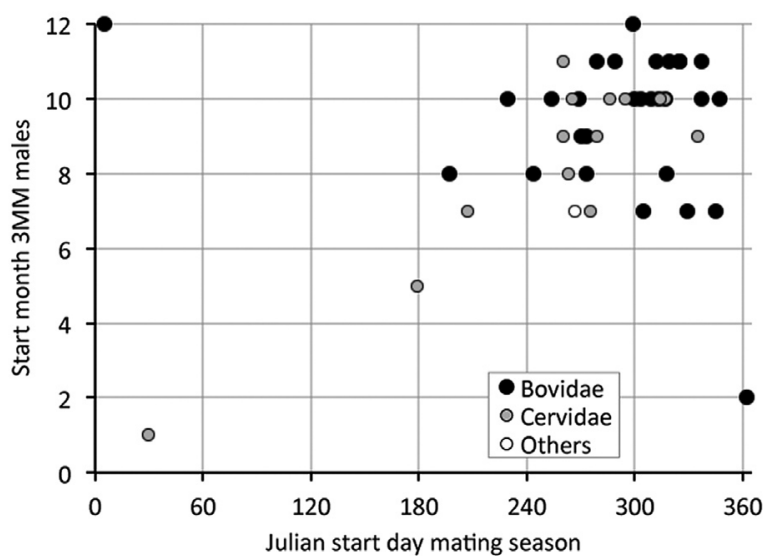

D

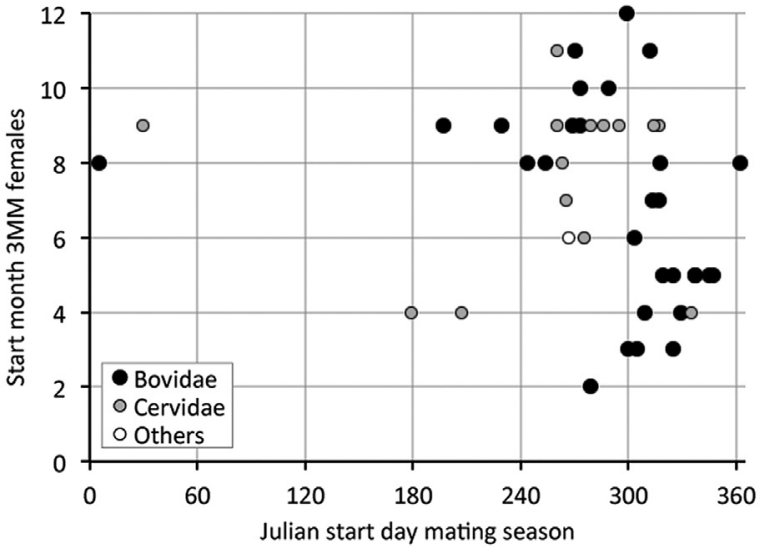

$\mathrm{F}$

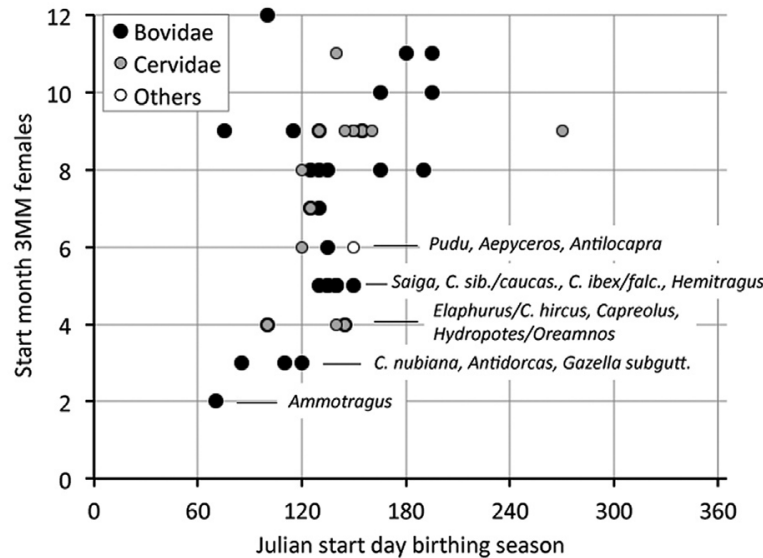

Fig. 6. Comparisons of the beginning of the mating season and the beginning of seasonal mortality in ruminant males (A), seasonally reproducing ruminant males $(\mathbf{B})$, ruminant females $(\mathbf{C})$ and seasonally reproducing ruminant females (D), and the beginning of the birthing season and beginning of seasonal mortality in ruminant females (E) and seasonally reproducing ruminant females (F). Note two species in the bovids in (B) that fit the overall patterns but appear as outliers due to the turn of the year. 
(Fig. 6D, lower right quadrant). In contrast, in these latter species seasonal mortality started around the beginning of the birthing period (Fig. 6F, lower left quadrant), and this group included a large number of caprids.

Neither maximum latitude, midrange latitude nor the BPB50 correlated significantly with the correlation coefficient of the monthly mortality between males and females, the $\rho_{\mathrm{mf}}$, in all ruminants $(P \geq 0.997$, Table 2$)$. The patterns of these relationships appeared to differ between bovids and cervids (Fig. 7). In bovids, the relationship with BPB50 was positive $(P=0.002$, Fig. 7 A, Table 2$)$, indicating that less seasonal reproducing species have more similar patterns of seasonal mortality. Correspondingly, the relationship of latitude with the $\rho_{\mathrm{mf}}$ was negative (in species with a distinct seasonal mortality, $3 \mathrm{MM}>0.4, P<0.023$, Fig. 7C). In cervids, the patterns tended towards the opposite direction (Fig. 7B and D), but were not significant (Table 2).

\section{DISCUSSION}

In this study, we analysed the pattern of seasonal mortality in captive wild ruminants, and established the $3 \mathrm{MM}$ as a quantitative measure of the degree of seasonality in overall mortality.

\section{Seasonal Mortality and Life Expectancy}

Generally, the degree of seasonal mortality was not related to the relative life expectancy [Müller et al., 2011], suggesting that the fact that species differ in their seasonal mortality patterns does not influence husbandry success per se. Therefore, we do not generally imply that existing patterns of seasonal mortality indicate shortcomings in ruminant husbandry, but identify some biological characteristics that may be related to such seasonal patterns. To evaluate husbandry success, other parameters such as life expectancy [Müller et al., 2011] or senescence patterns in comparison to free-ranging conspecifics are relevant. In this respect, zoo ruminants typically show lower senescence rates and higher longevities than their free-ranging conspecifics [Lemaître et al., 2013; Tidière et al., 2016]. Knowledge about seasonal distribution of mortality, in contrast, enhances our understanding of physiological and behavioural characteristics that not only shape mortality patterns in the wild, but also when housed in zoos.

Given the large number of potential influence factors, and the necessity to evaluate not only the whole dataset but ruminant groups and sexes individually, our approach is that of an exploratory investigation. Given the large scatter in many of the significant relationships, it is always necessary to consider an individual species in itself when addressing questions about its particular husbandry (see for example the difference between individual bovid species and sexes in Figs. 1 and 2). Therefore, one cannot claim that the general patterns described in the subsequent sections apply consistently to all species, but only that they represent general trends.

\section{Seasonal Mortality, Climate, and Geographic Species Origin}

Perhaps the most surprising result of our study was that although the majority of seasonal mortality (note that this does not mean the majority of overall mortality) occurred in winter months, the expected relationship of the degree of seasonal mortality with the latitude of a species' origin-or another climate proxy such as the mean annual temperature in the natural habitat-was not found. Species from lowerlatitude habitats do not show a higher degree of seasonal mortality in zoos than species from higher latitudes. The indoor housing of tropical species during winter might explain the lack of the expected pattern. Therefore, the data suggest that while climatic conditions in winter affect zookept ruminants, this is a general climatic effect to which no

TABLE 2. Relationships ( $t$-statistic $[n], P)$ of various measures with the correlation coefficient of monthly above-baseline mortality of males and females $\left(\rho_{\mathrm{mf}}\right)$ of captive wild ruminants

\begin{tabular}{|c|c|c|c|}
\hline & All ruminants & Bovids & Cervids \\
\hline \multicolumn{4}{|l|}{ All species } \\
\hline Maximum latitude & $\begin{aligned} t & =0.8[80] \\
P & =0.404\end{aligned}$ & $\begin{array}{c}t=-1.1[60] \\
P=0.290\end{array}$ & $\begin{aligned} t & =1.7[16] \\
P & =0.118\end{aligned}$ \\
\hline Midrange latitude & $\begin{array}{c}t=-0.0[80] \\
P=0.997\end{array}$ & $\begin{array}{c}t=-1.5[60] \\
P=0.131\end{array}$ & $\begin{aligned} t & =1.3[16] \\
P & =0.227\end{aligned}$ \\
\hline BPB50 & $\begin{aligned} t & =1.3[85] \\
P & =0.214\end{aligned}$ & $\begin{aligned} t & =3.2[61] \\
P & =0.002\end{aligned}$ & $\begin{array}{c}t=-1.3[19] \\
P=0.220\end{array}$ \\
\hline Species $3 \mathrm{MM}>0.4$ & & & \\
\hline Maximum latitude & $\begin{array}{c}t=-0.5[59] \\
P=0.648^{*}\end{array}$ & $\begin{array}{c}t=-2.4[45] \\
P=0.020\end{array}$ & $\begin{aligned} t & =1.2[11] \\
P & =0.248\end{aligned}$ \\
\hline Midrange latitude & $\begin{array}{c}t=-0.4[59] \\
P=0.710^{*}\end{array}$ & $\begin{array}{c}t=-2.4[45] \\
P=0.023\end{array}$ & $\begin{aligned} t & =0.7[11] \\
P & =0.486\end{aligned}$ \\
\hline BPB50 & $\begin{aligned} t & =2.0[65] \\
P & =0.050^{*}\end{aligned}$ & $\begin{aligned} t & =4.2[47] \\
P & <0.001\end{aligned}$ & $\begin{aligned} t & =0.0[14] \\
P & =0.972\end{aligned}$ \\
\hline
\end{tabular}

Analyses reported for Ordinary Least Squares in cases where $\lambda$ not significantly different from zero. * Results of Phylogenetic Generalized Least Squares when $\lambda$ significantly different from zero. 
group of ruminant species is particularly susceptible due to husbandry regimes. Additionally, given that baseline mortality, that is non-seasonal mortality, averaged at more than 0.50 , seasonal influences appear to generally play a minor role.

Our findings correspond to those of a single facility with higher mortalities in colder months [Gull et al., 2010], and to findings in domestic animals (see Introduction) and humans [Healy, 2003; Sheridan and Kalkstein, 2010; Ebi and Mills, 2013] that higher mortalities are often observed during colder times of the year. For an individual species reported to be susceptible to cold, the giraffe (Giraffa camelopardalis) [Walker et al., 1987; Rieches, 1997a; Clauss et al., 1999], the individual data in Table S2 indicates a seasonal mortality category 3 for males, with an accumulation of deaths in winter. The situation is similar for okapi (Okapia johnstoni). These observations match a recent finding that giraffids do not show seasonal adaptation in the insulation of their fur

\section{Bovids}

A

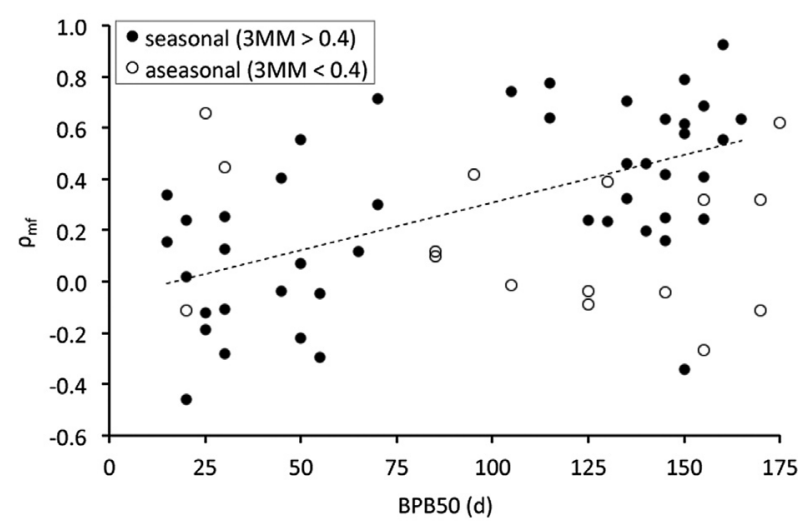

C

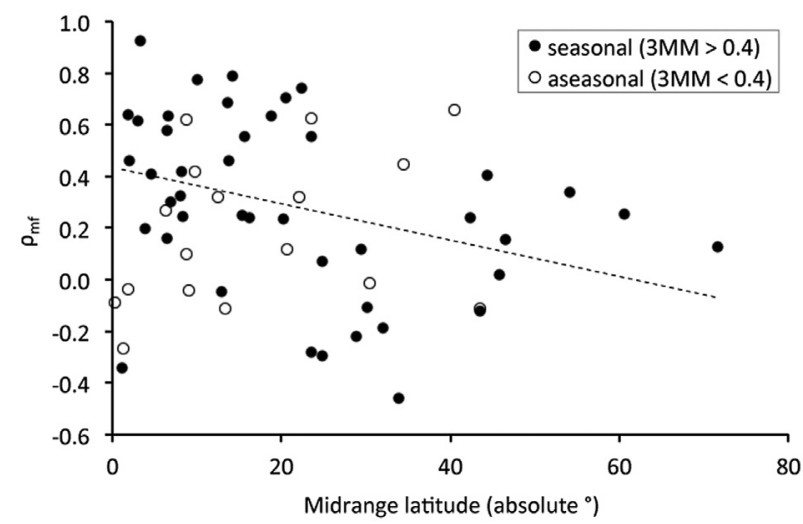

coat [Langman et al., 2015]. Similarly, for another species noted to be susceptible to cold, the gerenuk (Litocranius walleri) [Smith et al., 1997], a seasonal mortality peak in winter is evident (Table S2). Nevertheless, the high baseline mortalities-in giraffe, 0.74 for males and 0.80 for females-indicate that the seasonal component of mortality should not be over-emphasized. For many ruminant species, husbandry guidelines specify that stables or indoor enclosures with heat provision are necessary in the temperate zone [Kranz and La, 1997; Smith et al., 1997; Williamson, 1997]. In contrast, other animals appear particularly adapted to cold climates. The mountain goat (Oreamnos americanus), for example, displays a particular seasonal increase in fur insulation [Langman et al., 2015], and in this species, although it showed evidence of seasonal mortality, mortality was not related to the winter but summer months (Table S2), suggesting a susceptibility to warm temperatures in this species similar to domestic cattle.

\section{Cervids}

B
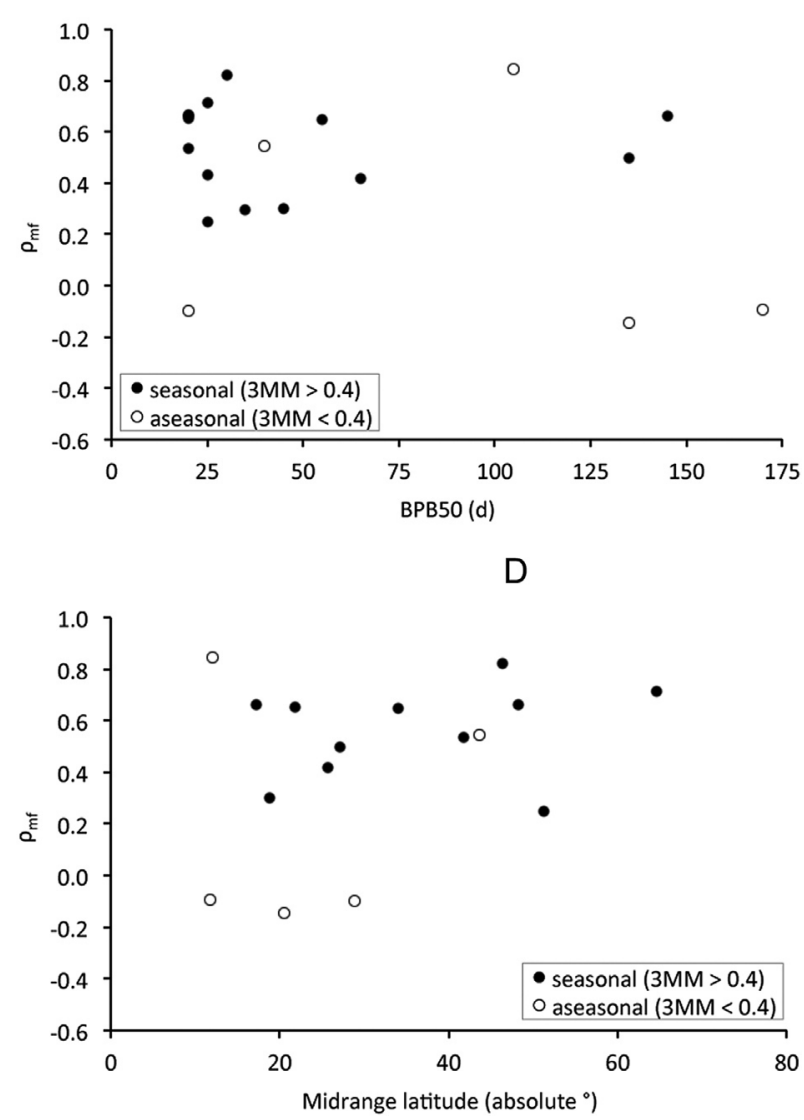

Fig. 7. Relationships between (A, B) the number of days in which $50 \%$ of all births occur in captivity (BPB50, as a measure of reproductive seasonality) or (C,D) the midrange latitude (as absolute ${ }^{\circ}$ ) of the natural habitat and the correlation of the monthly mortality between males and females $\left(\rho_{\mathrm{mf}}\right.$, as a measure of how similar the mortality pattern is between the sexes) in bovids $(\mathbf{A}, \mathbf{C})$ and cervids $(\mathbf{B}, \mathbf{D})$. Note the slightly opposite trends between bovids (indicated for seasonal species with regression lines) and cervids, which indicates that the patterns of monthly mortality of the sexes are more dissimilar in bovids from higher latitudes/with a more distinct reproductive seasonality, whereas they are more similar in cervids from higher latitudes. 


\section{Seasonal Mortality and Reproductive Biology}

Actually, the few significant relationships that link the seasonal mortality pattern to a biological characteristic point towards an influence of the mating system-very distinctively in males, and less distinctively in females. Mating type, sexual size dimorphism, breeding group size as well as the seasonality of reproduction (as classified by categories or measured as BPB50) showed some association with $3 \mathrm{MM}$ in males (Table 1). Latitude was positively related to seasonal mortality, indicating that species from higher latitudes actually had a more pronounced seasonal mortality. This finding is consistent with the observation that $3 \mathrm{MM}$ correlates with the degree of reproductive seasonality, as latitude is also positively correlated to the degree of reproductive seasonality [Zerbe et al., 2012]. Findings of a significant positive effect of body mass in male cervids, and a significant negative effect of body mass in female ruminants in general, are in line with this general observation. Even the finding of a general positive relationship of $\%$ grass in the natural diet with $3 \mathrm{MM}$ matches this finding, as the family responsible for this pattern, the bovids, hardly have seasonally reproducing species that are also browsers (Fig. S2). The evident implication of all these findings is that males most likely experience increased mortality in association with the rutting period, and that females either follow this pattern, or display an accumulation of mortality around the seasonal birthing period. Depending on the herd composition, higher male mortality in multi-male herds may be due to actual combat; alternatively, because such species are often mainained in single-male herds, this mortality is most likely linked to intrinsic, physiological stressors associated with rutting [Miquelle, 1990] that lead to low food intakes and potentially immunological compromise during the rut.

An unexpected finding of the present study was that the general pattern of rut-related seasonal mortality apparently differed between bovids and cervids. In cervids, the onset of seasonal mortality paralleled the onset of the rutting season in males, and it was not associated with the birthing period in females. Additionally, in cervids, the mortality patterns of males and females were generally more similar than in bovids (Fig. $7 \mathrm{~A}$ and $\mathrm{B}$ ), and the onset of $3 \mathrm{MM}$ was comparatively similar (Fig. S3B). Thus, females seem to be directly affected in the timing of their seasonal mortality by the rutting activity of males. In the zoo literature, this fact is reflected in the recommendation that enclosures for cervids should comprise passages of narrowly-spaced fencing that allows females to easily outmaneuver antlered males [Williamson, 1997]. A more ideal alternative, with a core enclosure of females that can have access to several separate enclosures containing single males during the rut, without allowing the males the reciprocal access to the core enclosure, should not go unmentioned. Such a system would correspond to a reproductive strategy where cervid males dominate leks, as for example reported in a certain proportion of red deer [Carranza et al., 1990].

The findings in bovids indicate a different pattern than cervids. Bovids from higher latitudes, and hence more seasonally reproducing bovids, have a more divergent pattern of seasonal mortality between males and females (Fig. 7A and C). With respect to the onset of seasonal mortality, in a certain number of species the female seasonal mortality starts in the first half of the year (Fig. S3A). In spite of reports that females suffer in the wild during the rutting period [Geist, 1971; Reale et al., 1996], a large group of female bovids-including many caprids-appear to be less affected by male rutting in captivity in comparison to female cervids. One reason might be that, in many wild goat and sheep species, in contrast to most cervids, several males can be kept together with a group of females [Rieches, 1997b] even when space is limited. These males will fight with each other during the rutting season without inflicting serious injury, and may hence be less prone to harass females, whereas single cervid males may have no other vent for their testosteroneincreased aggressive potential than to attack females. To our knowledge, there are no specific recommendations about thresholds of enclosure size (and structure) that allow the maintenance of mixed gender groups of cervids with multiple males without danger of lethal combat during the rut. Some species of deer that are typically kept in pairs or small single-male breeding groups, such as pudu (Pudu puda) or roe deer (Capreolus capreolus), also showed a mortality pattern where female mortality was more linked to the birthing than the rutting season (Fig. 6F).

Many husbandry guidelines warn about aggressive males during the rutting period [Puschmann, 2004]. Our findings suggest that measures currently in practice to protect ruminants from climatic effects are effective, with no apparent undue susceptibility to seasonal mortality in tropical species. They also underline the relevance of measures that allow females to evade rutting males especially in species that are kept in strict harem groups, and emphasize the well-known dangerous potential of cervids in this respect.

\section{CONCLUSIONS}

1. The proportion of mortality that is the same across all months of the year in captive wild ruminants (baseline mortality) averages across species at slightly above 0.50 . Generally, seasonal mortality peaks represent only a small proportion of overall mortality. The degree of seasonal mortality is not related to overall husbandry success as measured by the relative life expectancy of species.

2. The occurring seasonal mortality in captive wild ruminants is not associated with a particular susceptibility of tropical 
species, but rather to seasonal reproductive strategies in ruminants from higher latitudes.

3. Differences in seasonal mortality patterns are evident between seasonally reproducing cervids and bovids. In contrast to the cervids, where male and female seasonal mortality is mostly linked to the timing of the rut, female seasonal mortality is dissociated from that of males in many bovid species (especially caprids) and rather linked to the birth period.

\section{REFERENCES}

Aguirre AA, Bröjer C, Mörner T. 1999. Descriptive epidemiology of roe deer mortality in Sweden. J Wildl Dis 35:753-762.

Allen RE, McCullough DR. 1976. Deer-car accidents in southern Michigan. J Wildl Manage 40:317-325.

Alvåsen K, Mörk MJ, Sandgren CH, Thomsen PT, Emanuelson U. 2012. Herd-level risk factors associated with cow mortality in Swedish dairy herds. J Dairy Sci 95:4352-4362.

Bronson FH. 1989. Mammalian reproductive biology. Chicago: University of Chicago Press.

Burnham KP, Anderson DR. 2001. Kullback-Leibler information as a basis for strong inference in ecological studies. Wildl Res 28:111-119.

Burnham KP, Anderson DR. 2002. Model selection and multimodel inference: a practical information-theoretic approach. New York: Springer.

Carranza J, Alvarez F, Redondo T. 1990. Territoriality as a mating strategy in red deer. Animal Behaviour 40:79-88.

Clauss M, Dierenfeld ES. 2008. The nutrition of browsers. In: Fowler ME, Miller RE, editors. Zoo and wild animal medicine Current therapy 6. St. Louis: Saunders Elsevier. p444-p454.

Clauss M, Suedmeyer WK, Flach EJ. 1999. Susceptibility to cold in captive giraffe (Giraffa camelopardalis). Proc Am Ass Zoo Vet 183-186.

Crescio M, Forastiere F, Maurella C, Ingravalle F, Ru G. 2010. Heat-related mortality in dairy cattle: a case crossover study. Prev Vet Med 97:191-197.

Cronje HP, Reilly BK, MacFadyen ID. 2002. Natural mortality amoung four common ungulate species on Letaba Ranch, Limpopo Province, South Africa. Koedoe 45:79-86.

DelGiudice GD, Riggs MR, Joly P, Pan W. 2002. Winter severity, survival, and cause-specific mortality of female white-tailed deer in north-central Minnesota. J Wildl Manage 66:698-717.

DePerno CS, Jenks JA, Griffin SL, Rice LA. 2000. Female survival rates in a declining white-tailed deer population. Wildl Soc Bull 28:1030-1037.

Ebi KL, Mills D. 2013. Winter mortality in a warming climate: a reassessment. Wiley Interdisciplinary Reviews: Climate Change 4:203-212.

Flach EJ. 2008. Gastrointestinal nematodiasis in hoofstock. In: Fowler ME, Miller RE, editors. Zoo and wild animal medicine: current therapy. Saint Louis, Missouri: Saunders Elsevier. p416-p422.

Freckleton RP, Harvey PH, Pagel M. 2002. Phylogenetic analysis and comparative data: a test and review of evidence. Am Nat 160:712-726.

Fritz SA, Bininda-Emonds OR, Purvis A. 2009. Geographical variation in predictors of mammalian extinction risk: big is bad, but only in the tropics. Ecol Lett 12:538-549.

Fryxell JM. 1987. Food limitation and demography of a migratory antelope, the white-eared kob. Oecologia 72:83-91.

Gavin TA, Suring LH, Vohs PA, Meslow EC. 1984. Population characteristics, spatial organization, and natural mortality in the Columbian whitetailed deer. Wildl Monogr 91:3-41.

Geist V. 1971. Mountain sheep. Chicago: University of Chicago Press.

Gogarten JF, Brown LM, Chapman CA, et al. 2012. Seasonal mortality patterns in non-human primates: implications for variation in selection pressures across environments. Evolution 66:3252-3266.

Gonzalez G, Crampe JP. 2001. Mortality patterns in a protected population of isards (Rupicapra pyrenaica). Can J Zool 79:2072-2079.

Gull JM, Müller DWH, Michel A, Szabo D, Hammer S. 2010. Seasonal changes in mortality of captive artiodactyla populations in a desert zoo. Proceedings of the International Conference on Diseases of Zoo and Wild Animals 2:197-199.
Healy JD. 2003. Excess winter mortality in Europe: a cross country analysis identifying key risk factors. J Epidemiol Community Health 57:784-789.

Jones KE, Bielby J, Cardillo M, et al. 2009. PanTHERIA: a species-level database of life history, ecology, and geography of extant and recently extinct mammals. Ecology 90:2648. (Ecological Archives E2090-2184).

Kranz K, La Rue F. 1997. Small African bovids and chevrotains. Minimum husbandry guidelines for mammals. Silvers Spring MD: American Zoo and Aquarium Association (6 pp).

Langman VA, Langman SL, Ellifrit N. 2015. Seasonal acclimatization determined by non-invasive measurements of coat insulation. Zoo Biol 34:368-373.

Lemaître J-F, Gaillard J-M, Bingaman Lackey L, Clauss M, Müller DHW. 2013. Comparing free-ranging and captive populations reveals intraspecific variation in aging rates in large herbivores. Exp Gerontol 48:162-167.

McNay RS, Voller JM. 1995. Mortality causes and survival estimates for adult female Columbian black-tailed deer. J Wildl Manage 59:138-146.

Milton K. 1990. Annual mortality patterns of a mammal community in central Panama. J Trop Ecol 6:493-499.

Miquelle DG. 1990. Why don't bull moose eat during the rut? Behav Ecol Sociobiol 27:145-151.

Moen AN. 1978. Seasonal changes in heart rates, activity, metabolism, and forage intake of white-tailed deer. J Wildl Manage 42:715-738.

Morignat E, Gay E, Vinard J-L, Calavas D, Hénaux V. 2015. Quantifying the influence of ambient temperature on dairy and beef cattle mortality in France from a time-series analysis. Environ Res 140:524-534.

Müller DWH, Bingaman Lackey L, Streich WJ, Hatt J-M, Clauss M. 2010. Relevance of management and feeding regimens on life expectancy in captive deer. Am J Vet Res 71:275-280.

Müller DWH, Bingaman Lackey L, Streich WJ, et al. 2011. Mating system, feeding type and ex-situ conservation effort determine life expectancy in captive ruminants. Proc R Soc B 278:2076-2080.

Nass RD. 1977. Mortality associated with sheep operations in Idaho. J Range Manage 30:253-258.

Nelson ME, Mech LD. 1986. Mortality of white-tailed deer in Northeastern Minnesota. J Wildl Manage 50:691-698.

Nwosu CO, Madu PP, Richards WS. 2007. Prevalence and seasonal changes in the population of gastrointestinal nematodes of small ruminants in the semi-arid zone of north-eastern Nigeria. Vet Parasitol 144:118-124.

Orme D, Freckleton R, Thomas G, et al. 2010. Caper: comparative analyses of phylogenetics and evolution in R. R package version 04/r71 See http:// caperr-forger-projectorg/

Otis JS, Froehlich JW, Thorington RW. 1981. Seasonal and age-related differential mortality by sex in the Mantled Howler monkey, Alouatta palliata. Int J Primatol 2:197-205.

Owen-Smith N. 2008. Changing vulnerability to predation related to season and sex in an African ungulate assemblage. Oikos 117:602-610.

Pagel M. 1999. Inferring the historical patterns of biological evolution. Nature 401:877-884.

Pinheiro J, Bates D, DebRoy S, Sarkar D, R Development Core Team. 2011. Nlme: linear and nonlinear mixed effects models. R package version 3 1-102 Available at https://cranr-projectorg/web/packages/nlme/

Puschmann W. 2004. Zootierhaltung Tiere in menschlicher Obhut Säugetiere. Germany: Wissenschaftlicher Verlag Harri Deutsch.

Reale D, Bousses P, Chapuis JL. 1996. Female-biased mortality induced by male sexual harassment in a feral sheep population. Can J Zool $74: 1812-1818$.

Revell LJ. 2010. Phylogenetic signal and linear regression on species data. Methods Ecol Evol 1:319-329.

Rieches R. 1997a. Giraffes. Minimum husbandry guidelines for mammals. Silvers Spring MD: American Zoo and Aquarium Association.

Rieches R. 1997b. Goats and sheep. Minimum husbandry guidelines for mammals. Silvers Spring MD: American Zoo and Aquarium Association.

Sheridan SC, Kalkstein AJ. 2010. Seasonal variability in heat-related mortality across the United States. Natural Hazards 55:291-305.

Smith RC, Ruther D, Flanagan J, et al. 1997. Antelopes and gazelles. Minimum husbandry guidelines for mammals. Silvers Spring MD: American Zoo and Aquarium Association.

Team RDC. 2011. R: A language and environment for statistical computing. $\mathrm{R}$ Foundation for Statistical Computing, Vienna, Austria ISBN 3-900051-07-0, URL http://wwwR-projectorg/

Tidière M, Gaillard J-M, Berger V, et al. 2016. Comparative analyses of longevity and senescence reveal variable survival benefits of living in zoos across mammals. Sci Rep 6:36361. 


\section{Carisch et al.}

Vitali A, Segnalini M, Bertocchi L, et al. 2009. Seasonal pattern of mortality and relationships between mortality and temperature-humidity index in dairy cows. J Dairy Sci 92:3781-3790.

Walker BH, Emslie RH, Owen-Smith RN, Scholes RJ. 1987. To cull or not to cull: lessons from a Southern African drought. J Appl Ecol 24:381-401.

Williamson LR. 1997. Cervids. Minimum husbandry guidelines for mammals. Silvers Spring MD: American Zoo and Aquarium Association.
Zerbe P, Clauss M, Codron D, et al. 2012. Reproductive seasonality in captive wild ruminants: implications for biogeographical adaptation, photoperiodic control, and life history. Biol Rev 87:965-990.

\section{SUPPORTING INFORMATION}

Additional supporting information may be found in the online version of this article. 
Zoo Biology - Supporting Information

Seasonal mortality in zoo ruminants

Lea Carisch ${ }^{1}$, Dennis W. H. Müller ${ }^{2}$, Jean-Michel Hatt ${ }^{1}$, Laurie Bingaman Lackey ${ }^{3}$, E.

Eberhard Rensch $^{1}$, Marcus Clauss ${ }^{1}$, Philipp Zerbe ${ }^{1}$

${ }^{1}$ Clinic for Zoo Animals, Exotic Pets and Wildlife, Vetsuisse Faculty, University of Zurich, Winterthurerstrasse 260, 8057 Zurich, Switzerland

${ }^{2}$ Zoologischer Garten Halle GmbH, Fasanenstr. 5a, 06114 Halle, Germany

${ }^{3}$ World Association of Zoos and Aquariums (WAZA), Gland, Switzerland 


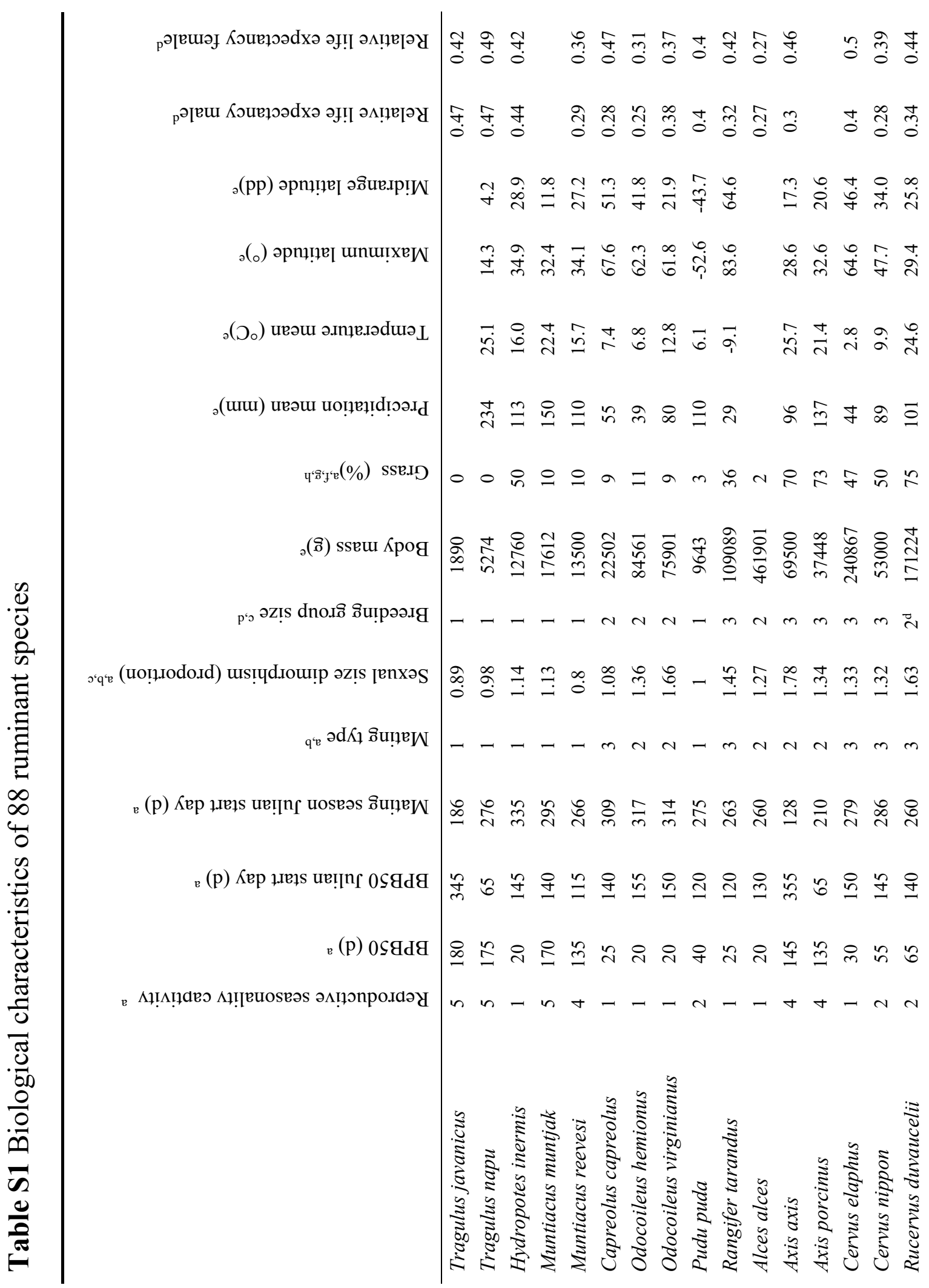




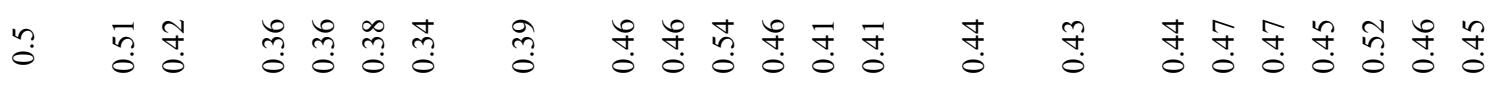

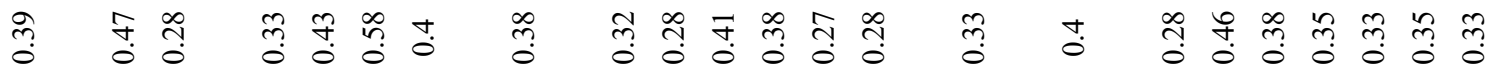

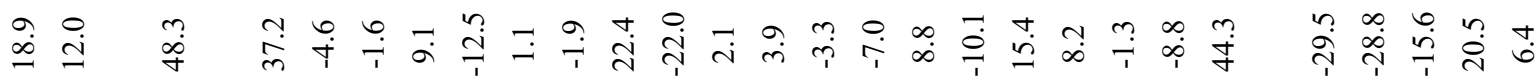

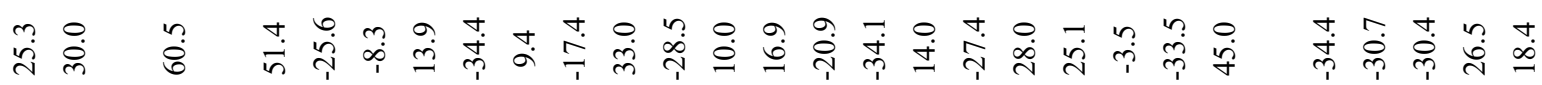

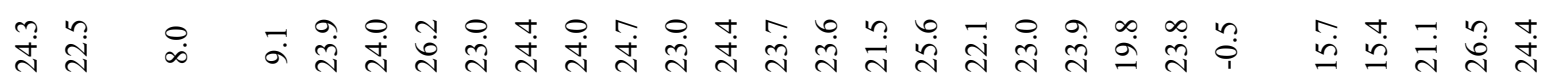

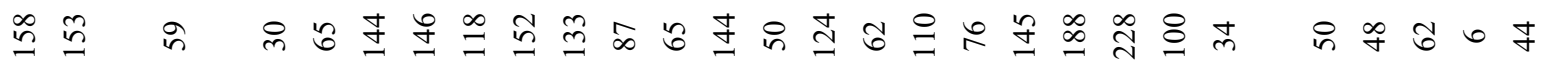

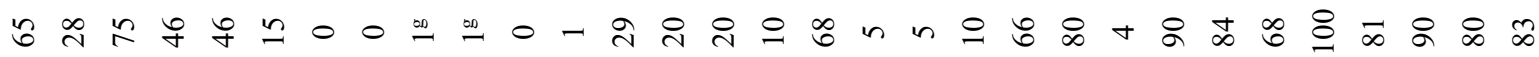

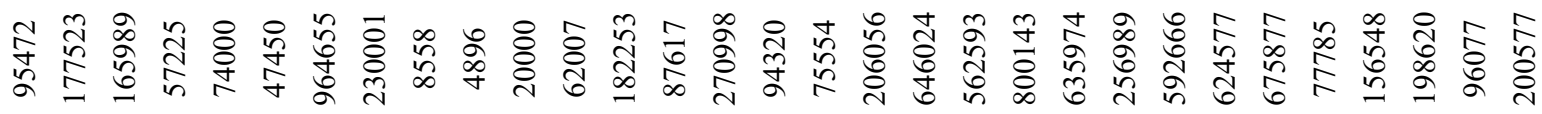

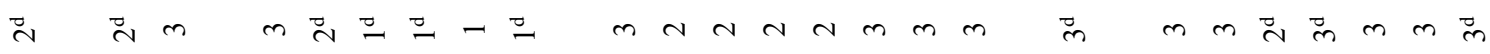

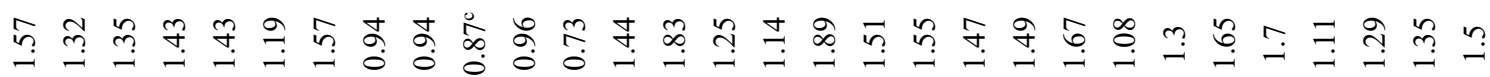

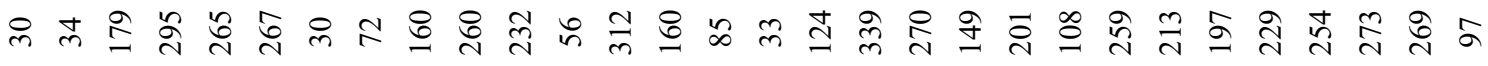

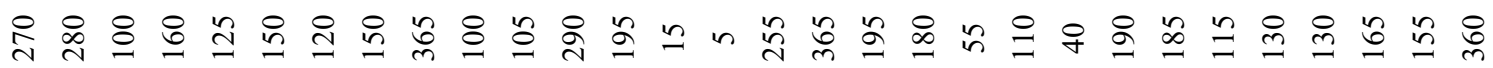

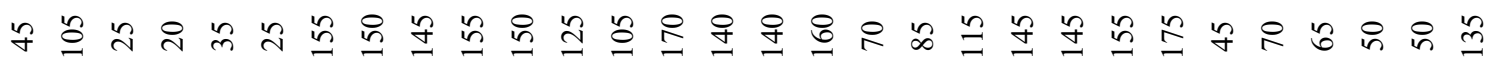

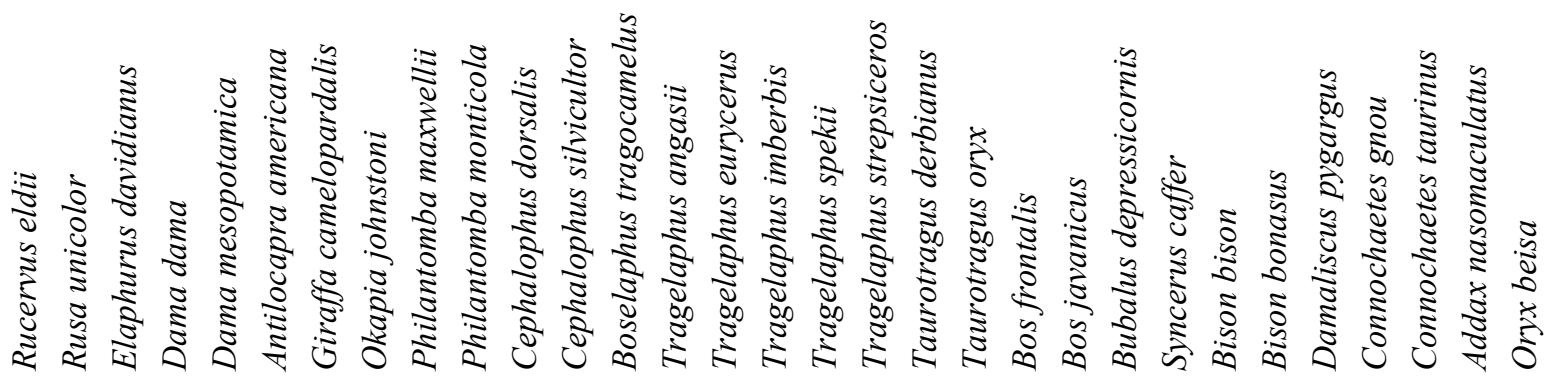




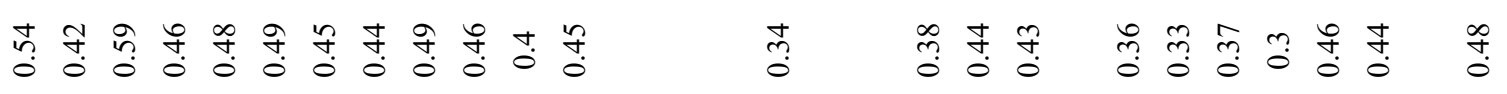

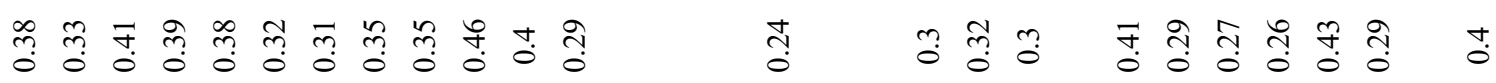

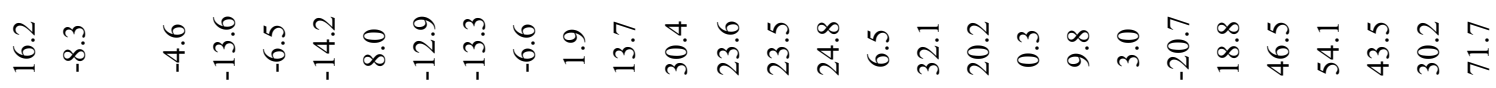

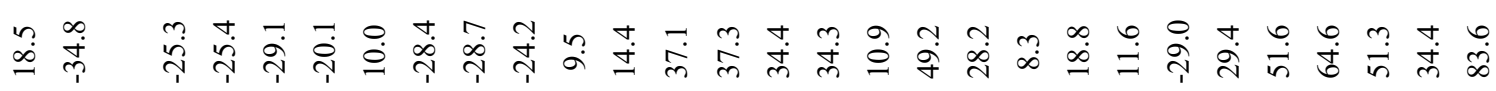

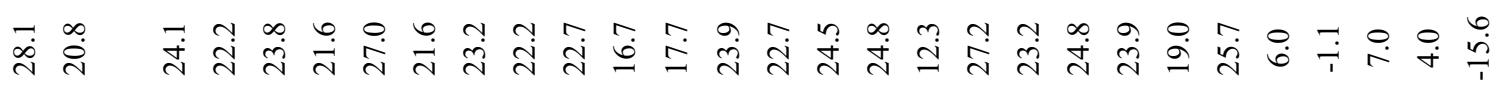
ㄱ

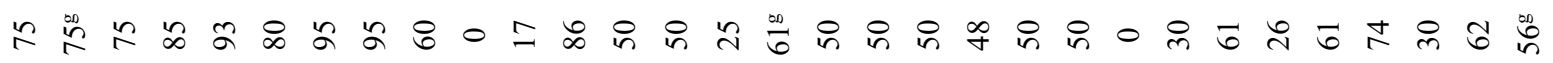

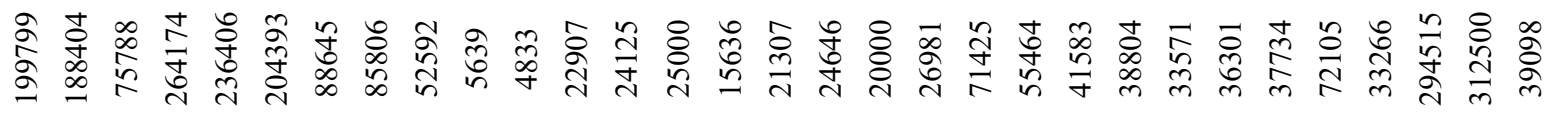

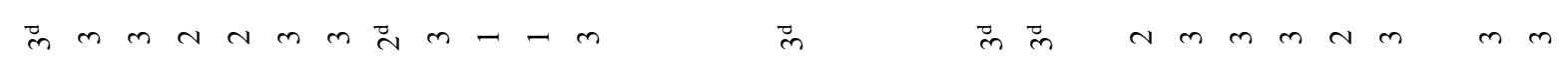

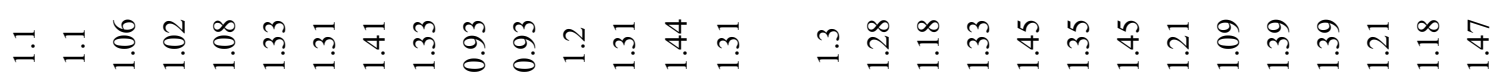

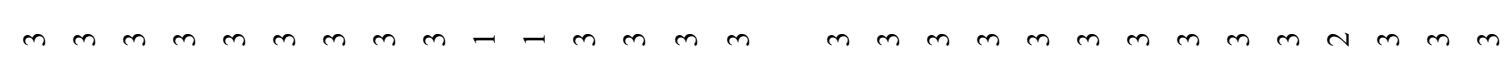

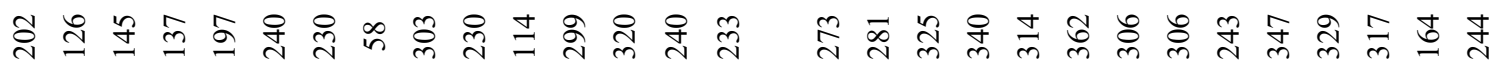

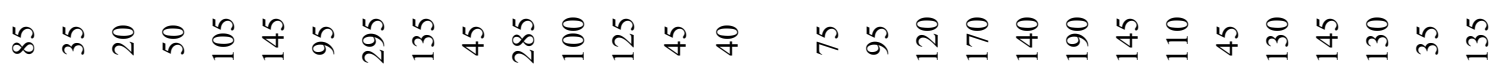

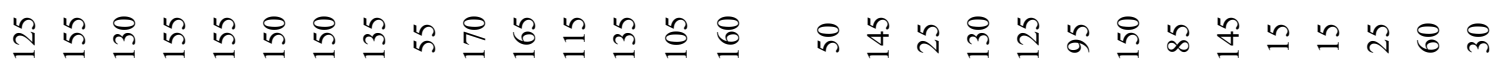

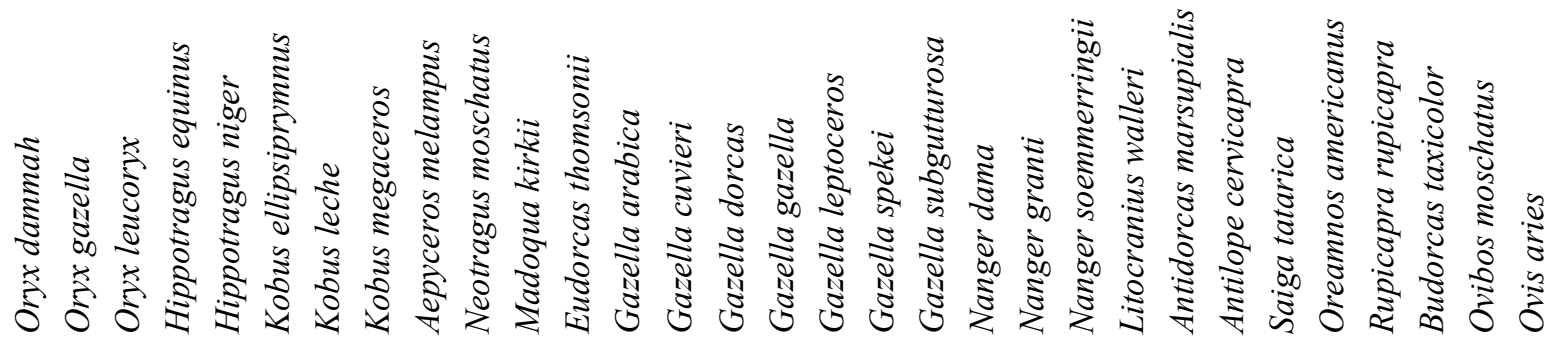




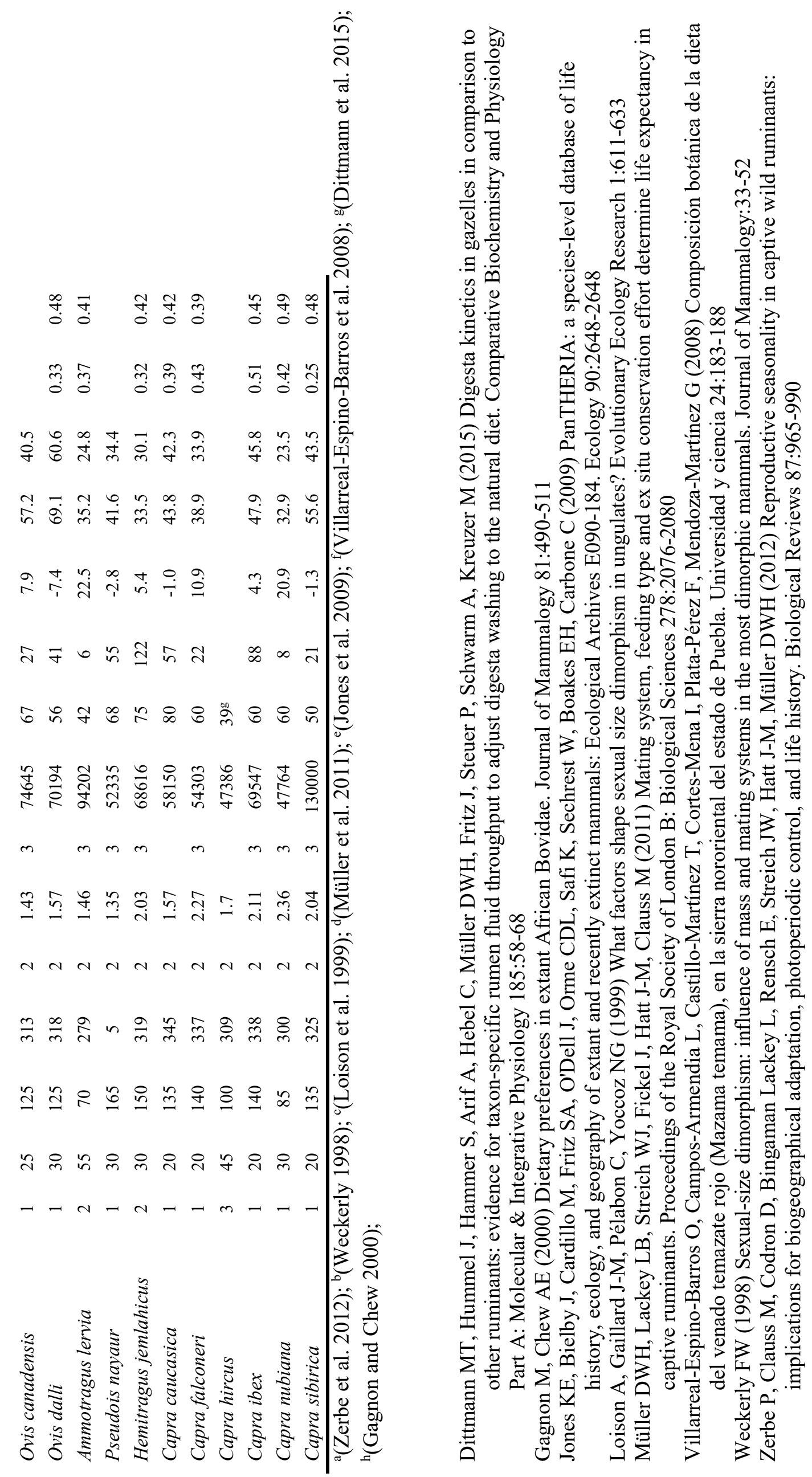




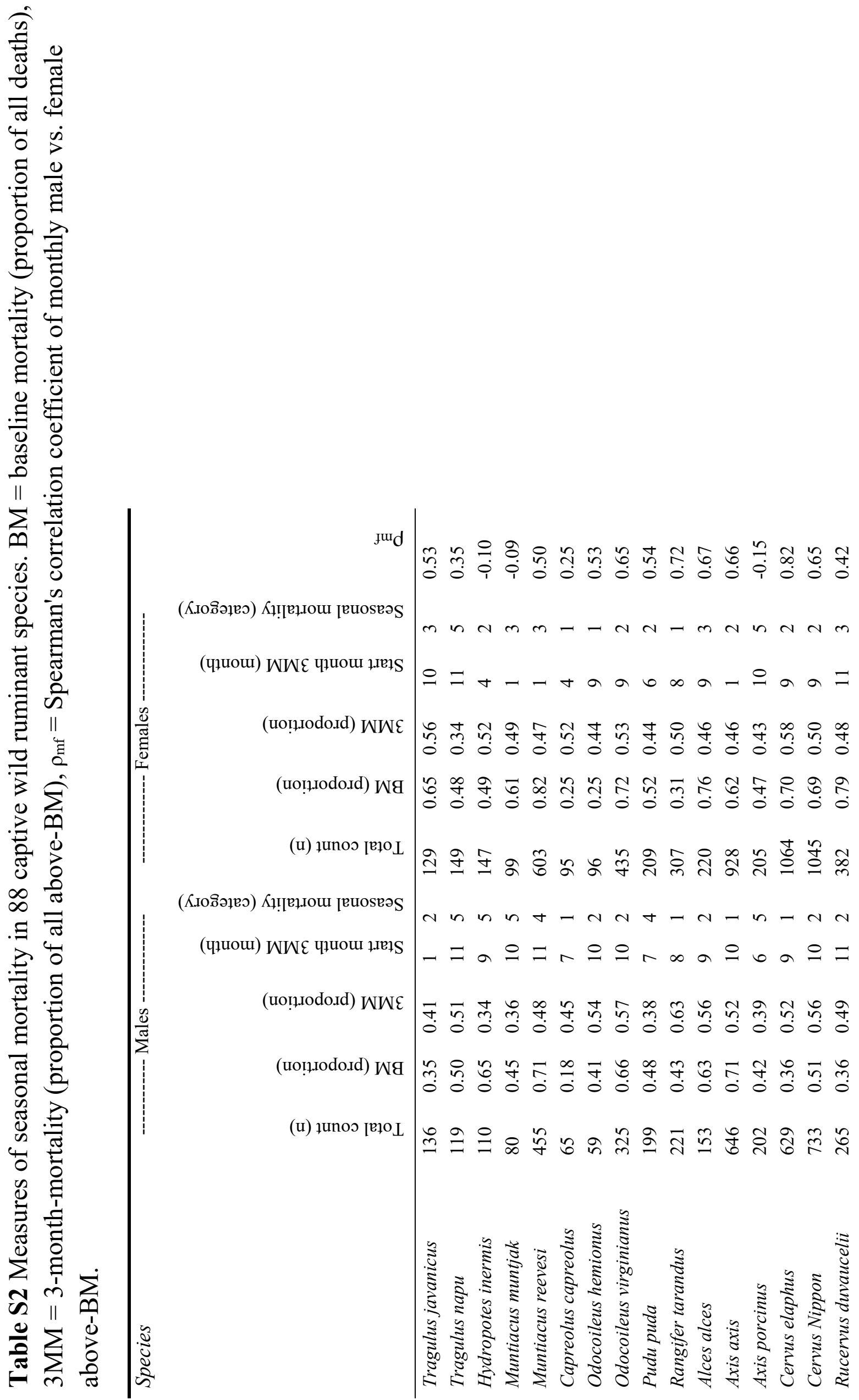




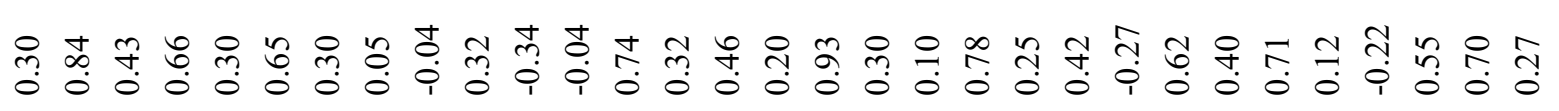

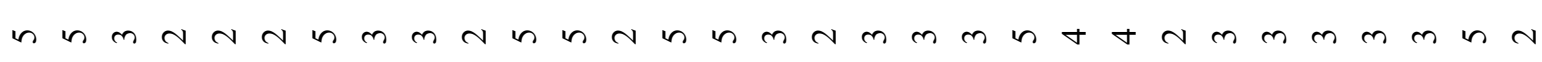

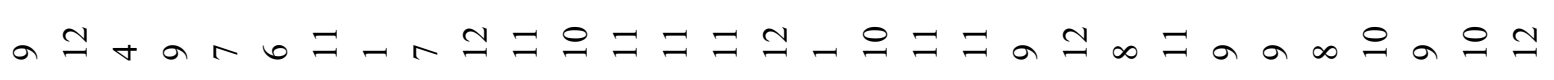

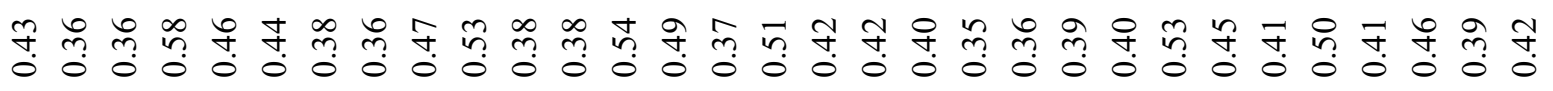

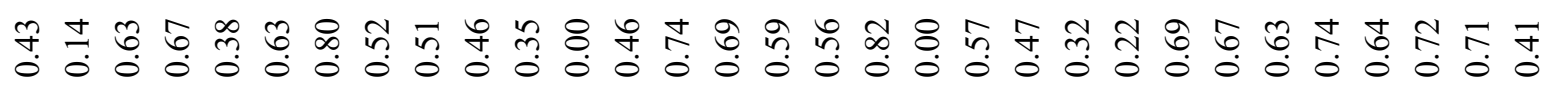

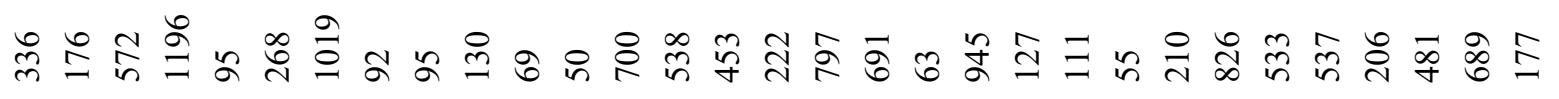

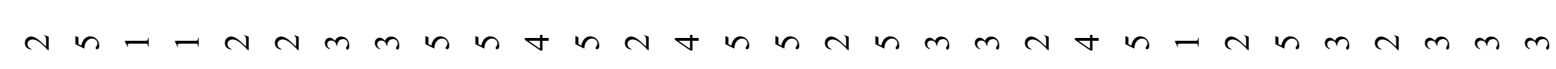

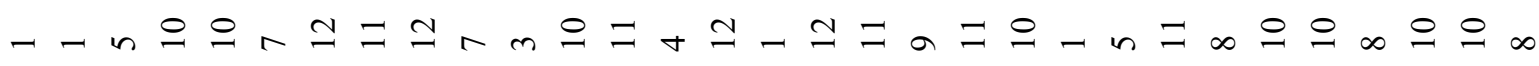

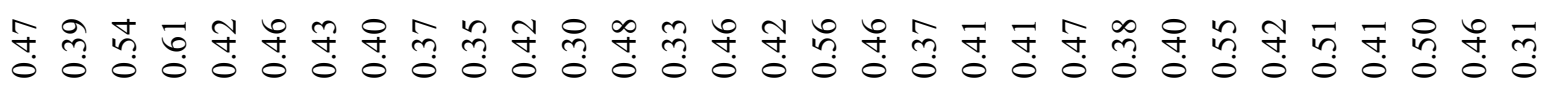

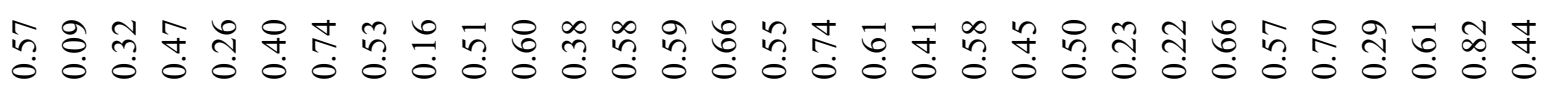

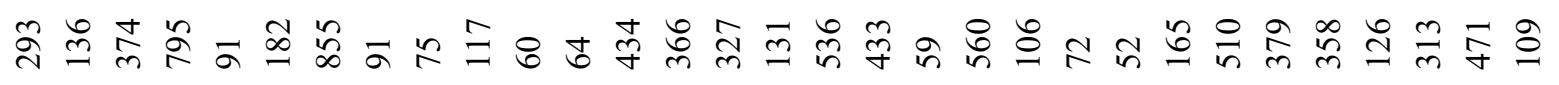

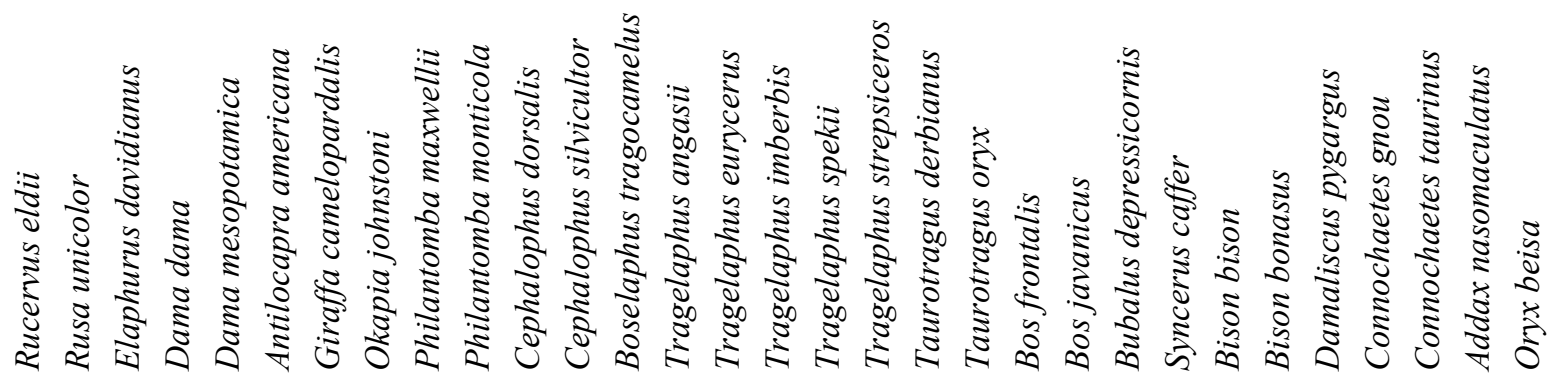




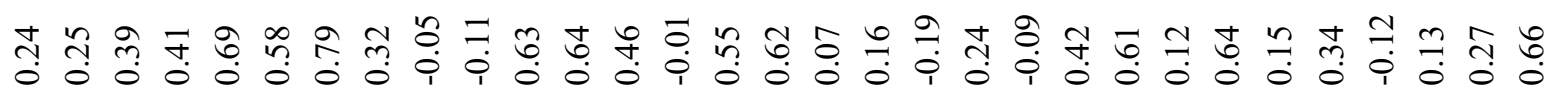

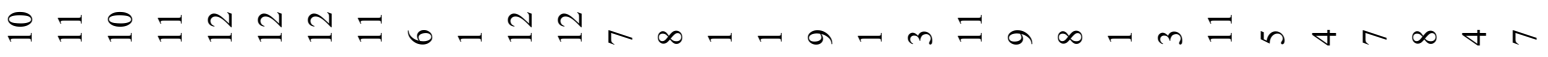

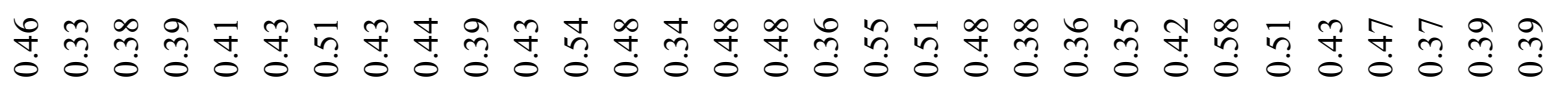

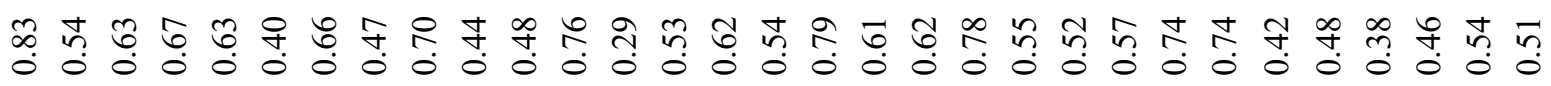

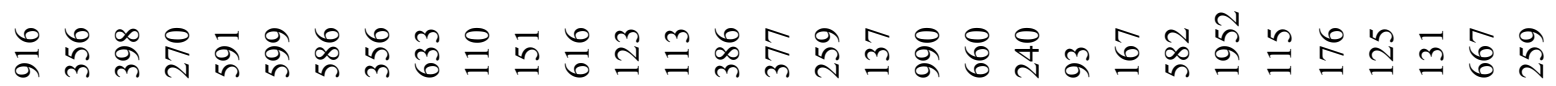

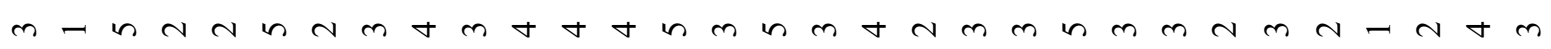

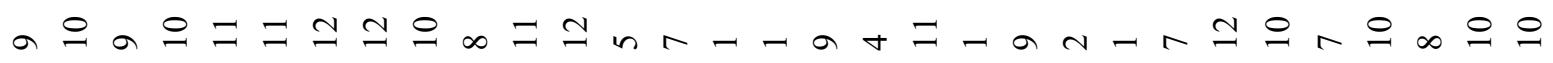

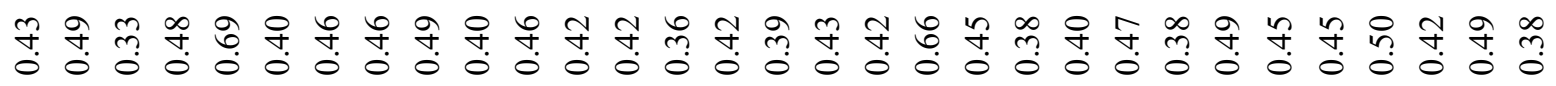

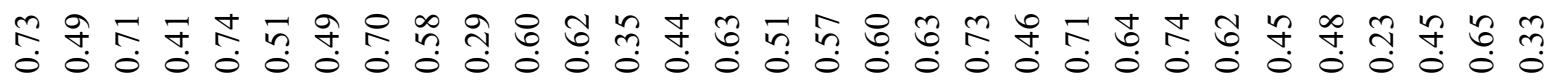

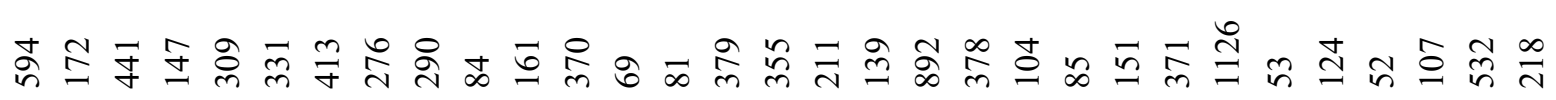

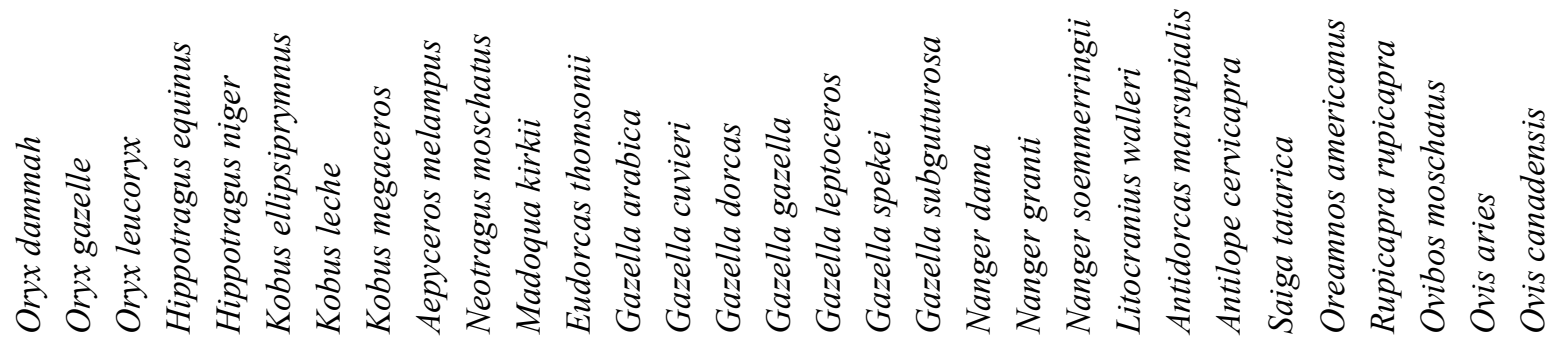



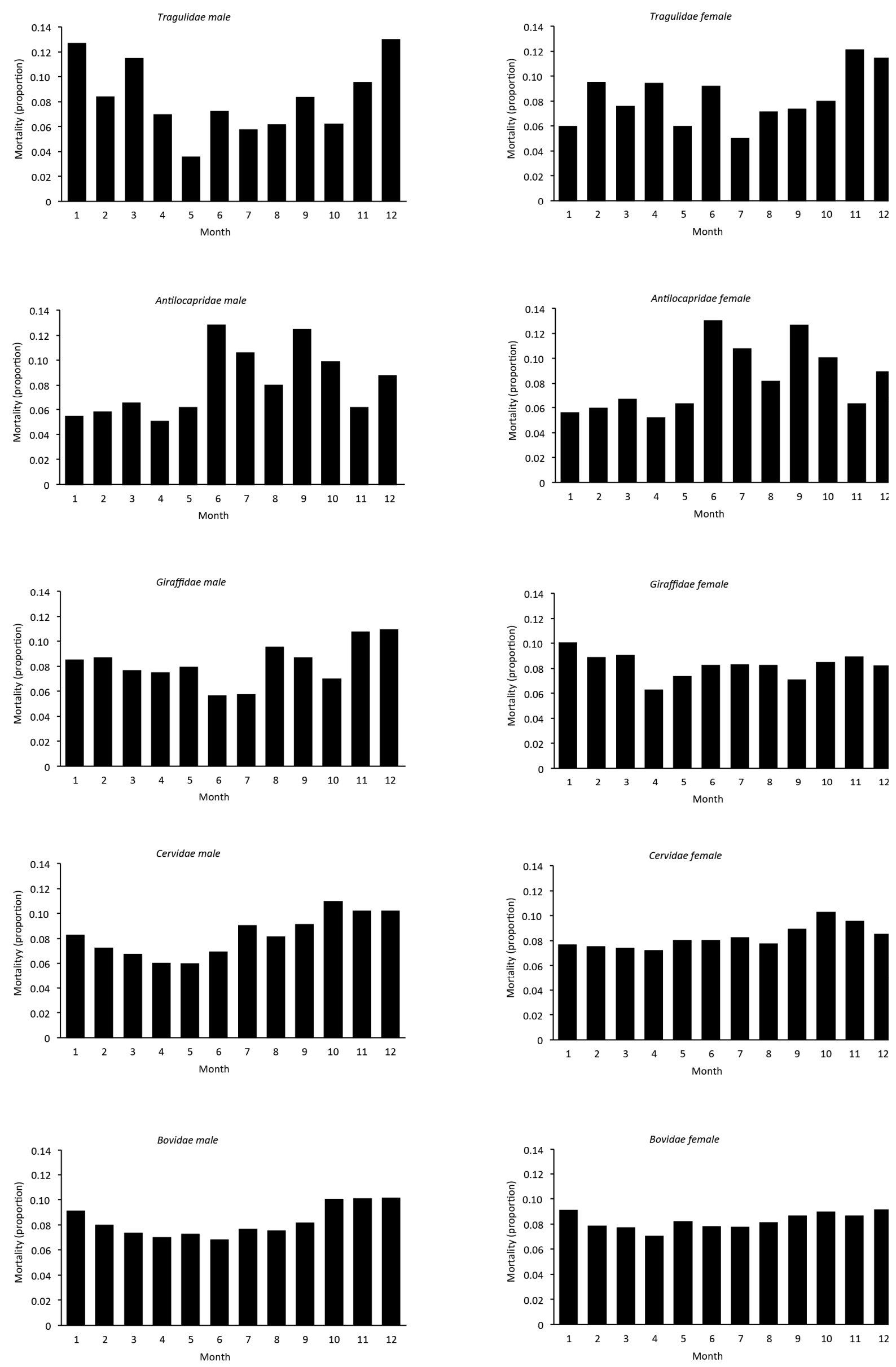

Figure S1 Monthly mortality in males and females of wild ruminant families. 
A

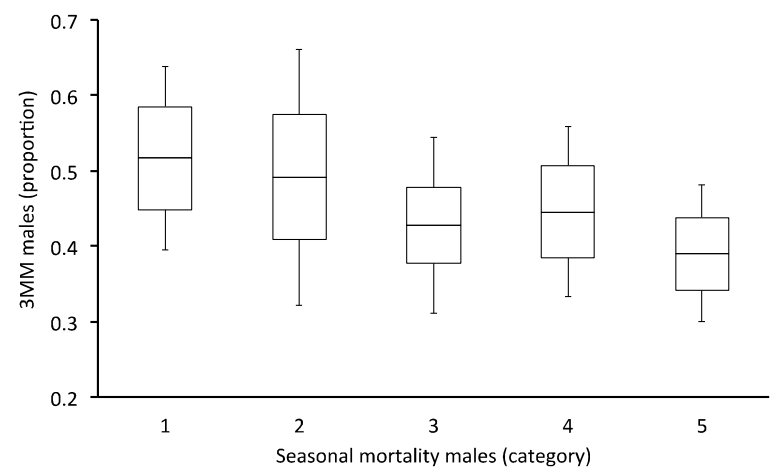

B

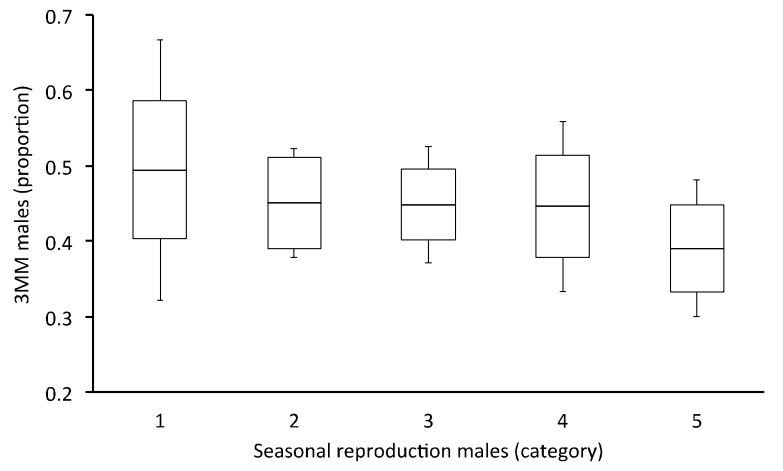

Figure S2 Comparison of (A) seasonal mortality categories (cf. Fig. 1) and (B) seasonal reproduction categories with the 3-month-mortaliy ( $3 \mathrm{MM}$, mean $\pm \mathrm{SD}$, minimum-maximum) as a measure of seasonal mortality in males of captive wild ruminant species.

A

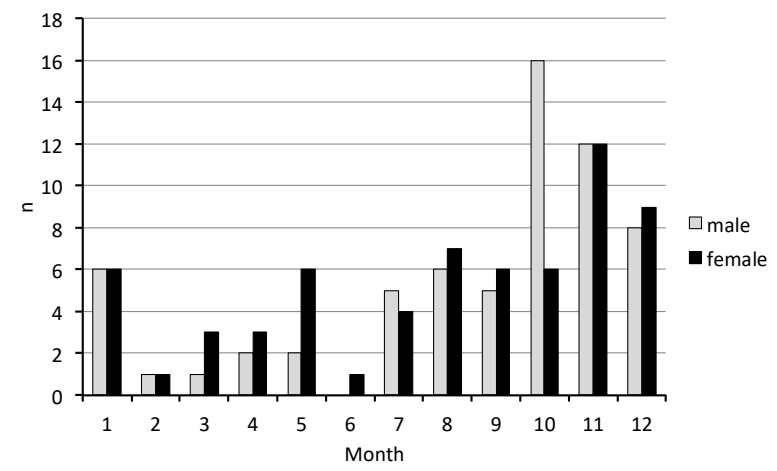

B

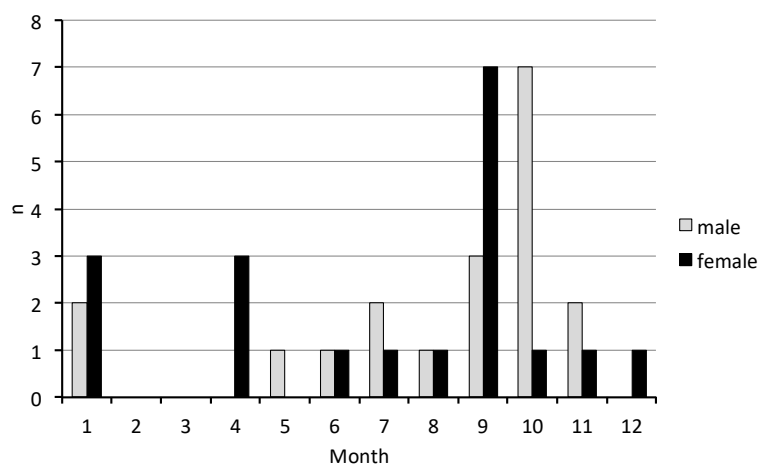

Figure S3 Distribution of the starting month of the 3-month-block of main above-baseline mortality across the year in both sexes of (A) bovid and (B) cervid species.

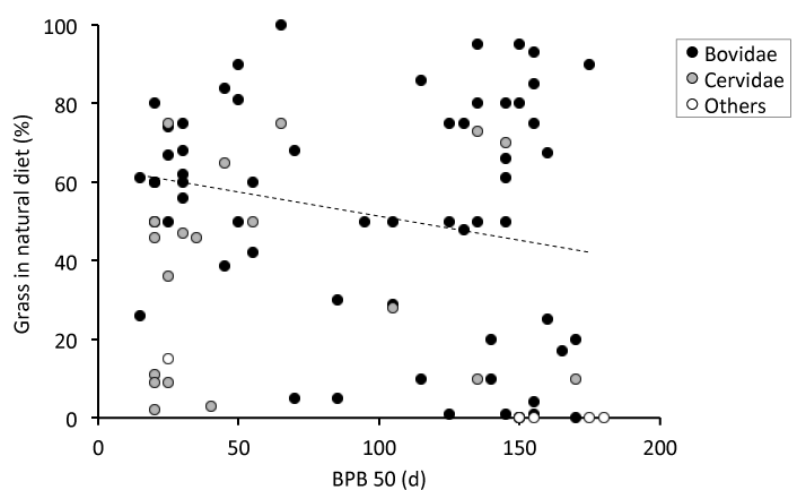

Figure S4 Relationship between the degree of seasonal reproduction (quantified as the BPB50) and the percentage of grass in the natural diet in the species included in the present study. Note the absence of seasonally reproducing (= low BPB50) browsing bovids. When evaluating the relationship, the phylogenetic signal $\lambda$ was always significant. There was no significant relationship in the overall dataset $(P=0.391)$, nor in cervids $(P=0.942)$. In bovids, OLS yielded a close-to-significant result $(P=0.087$; indicated by the regression line) whereas PGLS did not $(P=0.385)$, indicating a distinct phylogenetic pattern within bovids. 


\section{Curriculum Vitae}

Vorname Name

Geburtsdatum

Geburtsort

Nationalität

Heimatort

08/2003-06/2009

27.06.2009

$09 / 2010-12 / 2015$

30.12 .2015

$01 / 2016-06 / 2016$

$01 / 2016-06 / 2016$

07/2016 -
Lea Carisch

13.07.1990

Chur

$\mathrm{CH}$

Andiast

Kantonsschule (Kantonsschule Chur, Chur, Schweiz)

Kantonale Maturität (Kantonsschule Chur, Chur, Schweiz)

Veterinärmedizin (Schwerpunkt Kleintiere, Vetsuisse

Fakultät, Zürich, Schweiz)

Abschlussprüfung vet. med. (Vetsuisse Fakultät, Zürich, Schweiz)

Anfertigung der Dissertation

«Seasonal Mortality in Zoo Ruminants»

unter Leitung von Prof. Dr. M. Clauss

am Departement für Kleintiere, Abteilung für Zoo-, Heim- und Wildtiere der Vetsuisse-Fakultät, Universität Zürich

Direktor Prof. Dr. Jean-Michel Hatt

Doktorandin, Klinik für Zoo-, Heim- und Wildtiere, Tierspital Zürich, Zürich, Schweiz

Internship Kleintierreproduktion im Rahmen der

FVH/Residency-Ausbildung, Tierspital Zürich, Zürich, Schweiz 


\section{Von Herzen Danke}

Meinem Betreuer Marcus Clauss für die grossartige Unterstützung bei der Erstellung dieser Arbeit, für die stets freundliche und konstruktive Anleitung und Betreuung und insbesondere die Vermittlung der Neugierde an der Wissenschaft.

Philipp Zerbe - für Deine Geduld und Dein Verständnis, und Deinen unerschüttlichen Glauben an mich insbesondere dann, wenn ich es nicht tat, Deine stets aufbauenden Worte und die fortwährende Unterstützung in allen Bereichen.

Eberhard Rensch dank dessen technischem Fachwissen und Unterstützung die Entwicklung der Methodik möglich wurde.

Dennis Müller für die wertvollen Rückmeldungen und Beiträge für die Arbeit.

Jeanne Peter, für die freundliche und unkomplizierte Unterstützung im graphischen Bereich.

Professor Jean-Michel Hatt, Sandra Wenger, Monika Bochmann, Stamos Tahas, Maria Luisa Velasco Gallego, Sandra Mosimann und Nicole Merz, für die offene und herzliche Aufnahme ins Team.

Annina Balsiger, Louise Martin und Endre Pucora für die gemeinsamen statt einsamen Stunden im Büro.

Meiner Familie, ohne die ich nicht wäre wer und wo ich bin. Ihr gabt mir Wurzeln und Halt aber auch die Neugierde und den Mut neue und eigene Wege zu gehen. 